\title{
A GCM study of future climate response to aerosol pollution reductions
}

\author{
Silvia Kloster · Frank Dentener · Johann Feichter • \\ Frank Raes · Ulrike Lohmann · Erich Roeckner • \\ Irene Fischer-Bruns
}

Received: 18 November 2008/Accepted: 2 April 2009/Published online: 7 May 2009

(C) The Author(s) 2009. This article is published with open access at Springerlink.com

\begin{abstract}
We use the global atmospheric GCM aerosol model ECHAM5-HAM to asses possible impacts of future air pollution mitigation strategies on climate. Air quality control strategies focus on the reduction of aerosol emissions. Here we investigate the extreme case of a maximum feasible end-of-pipe abatement of aerosols in the near term future (2030) in combination with increasing greenhouse gas (GHG) concentrations. The temperature response of increasing GHG concentrations and reduced aerosol emissions leads to a global annual mean equilibrium temperature response of $2.18 \mathrm{~K}$. When aerosols are maximally abated only in the Industry and Powerplant sector, while other sectors stay with currently enforced regulations, the temperature response is $1.89 \mathrm{~K}$. A maximum feasible abatement applied in the Domestic and Transport sector, while other sectors remain with the current legislation, leads to a temperature response of $1.39 \mathrm{~K}$. Increasing GHG concentrations alone lead to a temperature response of $1.20 \mathrm{~K}$. We also simulate $2-5 \%$ increases in global mean precipitation among all scenarios considered, and the hydrological sensitivity is found to be significantly higher
\end{abstract}

S. Kloster · F. Dentener · F. Raes

European Commission, Joint Research Centre,

Institute for Environment and Sustainability, Ispra, VA, Italy

S. Kloster $(\varangle)$

Earth and Atmospheric Sciences Department, Cornell

University, Ithaca, NY, USA

e-mail:sk993@cornell.edu

J. Feichter · E. Roeckner - I. Fischer-Bruns

Max Planck Institute for Meteorology, Hamburg, Germany

U. Lohmann

Institute of Atmospheric and Climate Science, ETH Zurich,

Zurich, Switzerland for aerosols than for GHGs. Our study, thus highlights the huge potential impact of future air pollution mitigation strategies on climate and supports the need for urgent GHG emission reductions. GHG and aerosol forcings are not independent as both affect and are influenced by changes in the hydrological cycle. However, within the given range of changes in aerosol emissions and GHG concentrations considered in this study, the climate response towards increasing GHG concentrations and decreasing aerosols emissions is additive.

Keywords Climate change - Aerosol - Air pollution · Mitigation

\section{Introduction}

Anthropogenic aerosols are considered to be important contributors to observed changes in surface radiation and temperature over the last decades (Streets et al. 2006; Wild et al. 2005). Only the combined consideration of the radiative impacts of anthropogenic greenhouse gases (GHGs) and aerosol emissions allows global general circulation models (GCMs) to simulate realistically the observed increasing temperature trend over the last century (Nazarenko and Menon 2005; Roeckner et al. 1999). Therefore, future climate change will be controlled by increasing GHG concentrations in combination with changes in aerosol abundance. Anthropogenic aerosols cause a variety of adverse health impacts (WHO 2003). Consequently, nowadays aerosol emissions are largely policy regulated so that many regions that have encountered large increases in aerosol emissions in the past will reverse or already have reversed this trend towards decreasing aerosol emissions. A realistic assessment of ongoing and future climate 
change will thus rely on our capability to foresee trends in GHG concentrations and aerosol emissions and understand the combined impact of GHGs and aerosols on climate.

GHGs affect climate directly by absorbing radiation and warming the atmosphere. Aerosols affect climate directly and indirectly. The direct aerosol effect is caused by absorption and scattering of solar radiation. Indirectly, aerosols modify cloud radiative properties (cloud albedo effect; Twomey 1977) and cloud life cycle (cloud lifetime effect; Albrecht 1989). The direct aerosol effect of nonabsorbing aerosols always produces an overall cooling when introduced in the atmosphere, whereas partly absorbing aerosols can produce both a cooling or warming, depending on the aerosol properties and underlying surface albedo. The aerosol abundances are controlled by a combination of direct or precursor emissions, chemical reactions and meteorological processes (Forster et al. 2007)

A common concept to compare the potential climate impacts of individual components is radiative forcing (RF, e.g. IPCC 2001; Forster et al. 2007). RF is a measure of the radiative impact caused by an external perturbation introduced into the system, such as changes in GHG or aerosol concentration. The underlying assumption for using RF as a measure for potential climate change is that the global mean forcing $\Delta F$ is related to the equilibrium global mean surface temperature change, $\Delta T$, by

$\Delta T=\lambda \Delta F$

where the climate sensitivity $\lambda$ is a measure for the strength of climate feedback processes. The climate sensitivity is model dependent, primarily due to differences and large uncertainties in cloud feedbacks (Tsushima et al. 2006; Webb et al. 2006). However, for an individual climate model the RF concept assumes that the climate sensitivity is independent of the nature of the forcing. Several studies have tested this assumption utilizing different global climate models and different kind of perturbations, such as changes in solar output, changes in $\mathrm{CO}_{2}$ concentration or changes in ozone concentrations (Hansen et al. 1997; Forster et al. 2000; Stuber et al. 2001). The consensus of these studies, as discussed in Joshi et al. (2003), is that the climate sensitivity can be considered to be constant and independent of the forcing applied for homogeneously distributed forcing. However, this is not necessarily true for spatially inhomogeneous forcing. Indeed, previous studies have shown by analyzing three different GCMs that extra tropical forcings caused a larger global temperature response than tropical forcings (Joshi et al. 2003). Aerosol forcings are spatially much more inhomogeneous than GHG forcings due to the relatively short aerosol lifetime. Thus, for aerosols a different climate sensitivity can be expected compared to GHGs, which has indeed been reported in previous studies (Roberts and Jones 2004; Hansen et al. 2005).

A second issue is that the RF concept assumes that forcings are additive. This is not necessarily the case, when forcings are not independent of each other and depend on the climate conditions themselves. Feichter et al. (2004) have shown that there exists a relatively strong non-linear coupling between GHG forcing and aerosol forcing, as both forcings affect and are influenced by changes in the hydrological cycle. In contrast, similar simulations, however performed with different GCMs, found only a weak non-linear coupling and thus an almost additive system (Kirkevag et al. 2008; Gillett et al. 2004). Additionally, the aerosol system itself does not behave linearly. Predominantly, aerosols are internally mixed and the mixture is determining the aerosol properties. A previous modeling study (Kloster et al. 2008) using the same model and the same aerosol emissions scenarios as employed here showed that in the extreme case of only altering $\mathrm{SO}_{2}$ or carbonaceous emission, deviations from additivity for the top-ofthe atmosphere radiative forcing can reach up to $10 \%$ compared to an simulation changing both at the same time.

Aerosols are known to have a strong impact on precipitation as their forcing strongly impacts surface fluxes (Liepert et al. 2004; Feichter et al. 2004; Kirkevag et al. 2008). Thus, besides the previously mentioned climate sensitivity, the hydrological sensitivity, defined as the ratio between the percentage change in global mean precipitation and the change in global mean temperature, is another crucial parameter for evaluation of future climate change predictions as it might strongly depend on the forcing type applied.

In a recent study a multi-model projection of climate change from anthropogenic aerosol emissions following the SRES A1B story-line showed large intermodel differences, which were largely related to substantial differences in various emissions projections for short-lived species (Shindell et al. 2008). In all models $\mathrm{SO}_{2}$ emissions increased by 2030 . BC and OC emissions decreased in only one out of the three models by 2030. In this study we focus on the extreme case that by 2030 aerosols will be reduced using all presently available end-of-pipe technologies to a maximum feasible extent, i.e. without considering their costs. We investigate the role of these future aerosol reductions in terms of climate response in combination with increasing GHG concentrations. Separate simulations are performed in which only GHG concentrations or aerosol emissions or both in the same simulation are changed. We investigate: (i) how future air pollution mitigation will alter climate change; (ii) how comparable aerosol and GHG climate sensitivities and hydrological sensitivities are; (iii) whether aerosol and GHG forcings are independent of each other; (iv) whether the combined 
effect of GHG and aerosol forcing can be estimated by adding the individual contributions; and (v) how different the potential impact of maximum feasible reduction (MFR) air pollution mitigation strategies are when applied only in the Industry and Powerplant sector versus the Domestic and Transport sector. To answer the questions above, we perform equilibrium simulations with an updated version of the GCM ECHAM5-HAM. In Sect. 2 we describe the model and simulation setup. In Sect. 3 we give results for aerosol budgets, climate and hydrological sensitivity. Special attention is given to an analysis of the additivity of the climate response.

\section{Model and simulation Setup}

\subsection{Model setup}

We use the atmospheric general circulation model ECHAM5 (Roeckner et al. 2003) of the Max Planck Institute for Meteorology extended by a microphysical aerosol model HAM (Stier et al. 2005) coupled to a mixed layer ocean (Roeckner et al. 1995) to perform equilibrium climate simulations.

The spectral ECHAM5-HAM model is applied in a horizontal resolution of T63 $\left(1.75^{\circ} \times 1.75^{\circ}\right.$ on a Gaussian Grid) and a vertical resolution of 31 levels spanning from the surface up to $10 \mathrm{hPa}$. Monthly mean ocean heat transport is precalculated, allowing to reproduce the observed, present-day sea surface temperature climatology. In the subsequent simulations, the sea surface temperatures and the sea ice respond to the applied forcings, but the ocean heat transport is held constant.

The microphysical aerosol model HAM (Stier et al. 2005) is embedded into ECHAM5 and considers the aerosol compounds: sulfate $\left(\mathrm{SO}_{4}\right)$, black carbon $(\mathrm{BC})$, particulate organic matter (POM), sea salt and mineral dust. Emissions of sea salt, mineral dust and DMS are calculated interactively. Emissions of $\mathrm{BC}, \mathrm{POM}$ and $\mathrm{SO}_{2}$ from anthropogenic and natural sources are prescribed. The formation of sulfate from DMS and $\mathrm{SO}_{2}$ is calculated interactively within a sulfur chemistry model (Feichter et al. 1996) using prescribed offline oxidant concentrations (TM3 model; Dentener et al. 2005). Aerosol deposition processes (wet- and dry-deposition and sedimentation) are simulated interactively in dependence of aerosol size and composition. The aerosol fields interact with the radiation processes simulated in ECHAM5-HAM. The model includes an aerosol-cloud microphysical scheme and accounts for the semi-direct and indirect aerosol effects using a parametrization of the cloud aerosol interaction based on Lin and Leaitch (1997) as described in detail in Lohmann et al. (2007).

\subsection{Simulation Setup}

A control simulation (CONTROL) was performed over 100 years with present day (2000) GHG concentrations and present day aerosol and aerosol precursor emissions. Several future (2030) simulations were performed using different combination of anthropogenic aerosol and aerosol precursor emissions and GHG concentrations as summarized in Table 1. Each simulation was performed for 60 years and analyzed for the last 30 years in which an equilibrium state was reached in all simulations. Statistical significance of the simulated differences is measured by a student's $t$-test. For zonal averaged plots the error bars indicate the $95 \%$ confidence interval calculated with a standard student's $t$-test after the response was zonally averaged.

\subsubsection{Aerosol emission scenarios}

Emissions of anthropogenic $\mathrm{SO}_{2}, \mathrm{BC}$ and $\mathrm{OC}$ are taken from a recently developed aerosol emission inventory provided by IIASA (International Institute for Applied System Analysis), which considers two possible future developments: current legislation (CLE) and MFR (Cofala et al. 2007). CLE accounts for presently decided control legislations for future developments assuming full compliance. MFR assumes a full implementation of today's most advanced technologies worldwide. Non-technical structural measures, e.g. fuel shifts, are not considered. Both scenarios use the same underlying activity level

Table 1 Single simulation setup

\begin{tabular}{|c|c|c|c|}
\hline & $\begin{array}{l}\text { GHG } \\
\text { concentrations }\end{array}$ & $\begin{array}{l}\text { Aerosol } \\
\text { emissions }\end{array}$ & $\begin{array}{l}\text { Oxidant } \\
\text { concentrations }\end{array}$ \\
\hline CONTROL & 2000 & 2000 & 2000 \\
\hline$G H G+A E$ & 2030 & 2030 MFR & 2030 MFR \\
\hline$G H G+D T$ & 2030 & $\begin{array}{l}2030 \text { MFR for DT } \\
\text { sector }^{\mathrm{a}}\end{array}$ & 2000 \\
\hline$G H G+I P$ & 2030 & $\begin{array}{l}2030 \text { MFR for IP } \\
\text { sector }^{\mathrm{b}}\end{array}$ & 2000 \\
\hline$G H G$ & 2030 & 2000 & 2000 \\
\hline$A E$ & 2000 & 2030 MFR & 2030 MFR \\
\hline
\end{tabular}

Greenhouse gas (GHG) concentrations are set according to the IMAGE 2.2 implementation of the SRES B2 scenario (IMAGE 2001). Aerosol and aerosol precursor emissions are set according to IIASA (Cofala et al. 2007). Oxidant concentrations are from a previous TM3 model study (Dentener et al. 2005)

a Aerosol precursor and aerosol emissions in the Domestic and Transport sector are prescribed according to MFR 2030, all other sectors follow CLE 2030

b Aerosol precursor and aerosol emissions in the Industry and Powerplant sector are prescribed according to MFR 2030, all other sectors follow CLE 2030 
projection, which is based on current national perspectives on the sectoral economic and energy development up to the year 2030 in regions where data are available. For all other regions of the world the trends of future economic and energy developments of the IPCC SRES B2 MESSAGE scenario (Riahi and Roehl 2005; Nakicenovic et al. 2000) are applied. The emissions are given as national estimates per economic source sector (Road Transport, Non-Road Transport, Industry, Powerplants, and Domestic Use). Following Dentener et al. (2005), we gridded these on a $1^{\circ} \times 1^{\circ}$ Gaussian grid by utilizing the 1995 gridded sectoral distribution of the EDGAR3.2 global emission inventory (Olivier and Berdowski 2001). Emissions from international shipping, which are not included in the IIASA emission inventory, are added from a different inventory (Eyring et al. 2005). For MFR we choose the technology scenario TS1 ('CLEAN'), for CLE the technology scenario TS4 ('Business-as-Usual'), both with an underlying GDP growth of 3.1\%/year which is close to the GDP growth of the B2 scenario (2.8\%/year). For the conversion of the carbon mass of OC into the total mass of POM needed in ECHAM5-HAM a factor of 1.4 was applied. Climate sensitive natural emissions such as DMS, sea salt and dust emissions are simulated interactively in the model. Biomass burning emissions, which are partly of anthropogenic and partly of natural origin, are assumed to stay constant in the future. We do not consider the effects of climate change on the intensity or frequency of wildfires nor are changes in land use taken into account.

We focus our analysis on the year 2030 in comparison to present-day conditions (2000). The two different IIASA scenarios are denoted as CLE 2030 and MFR 2030 in the following. The changes in aerosol and aerosol precursor emissions and the resulting changes in aerosol burden for the different scenarios are discussed in Sect. 3.1.

\subsubsection{GHG and ozone scenarios}

For GHG concentrations we used the IMAGE 2.2 implementation of the SRES B2 scenario in accordance with the underlying activity scenario used for the aerosol emission projections by IIASA (Cofala et al. 2007). The SRES B2 storyline describes a world in which the emphasis is on local solutions to economic, social, and environmental sustainability. In terms of global annual mean anthropogenic $\mathrm{CO}_{2}$ emissions by 2100 , the SRES B2 scenarios fall in between SRES B1 and SRES A2 (Nakicenovic et al. 2000). For 2030 (2000) the following values were prescribed in ECHAM5 $\mathrm{CO}_{2}: 452$ (373) ppmv, $\mathrm{N}_{2} \mathrm{O}: 340$ (314) pptv, $\mathrm{CH}_{4}: 2.49$ (1.82) ppmv, CFC-11*: 184 (275) ppbv, CFC-12: 493 (549) ppbv, where CFC-11* accounts for the radiative effect of minor species, including a small contribution from natural sources (CF4). Monthly stratospheric and tropospheric ozone concentrations are prescribed as two-dimensional (latitude, height) distribution (Kiehl et al. 1999).

\subsubsection{Future simulations}

An overview of the different simulations performed in this study is given in Table 1. The future simulations $G H G+A E, G H G+D T$ and $G H G+I P$ consider different possible evolutions of anthropogenic aerosol precursor and aerosol emissions in the future (2030) in combination with expected consistent future GHG concentrations. In simulation $G H G+A E$ it is assumed that anthropogenic aerosol precursor and aerosol emissions follow the MFR 2030 scenario. To assess the separate impacts of emission sectors, we perform one simulation $(G H G+D T)$ where the Domestic and Transport sector follows MFR 2030 and the other sectors follow CLE 2030. In contrast, in the $G H G+I P$ simulation the Industry and Power generation sector follows MFR 2030, and the other sectors CLE 2030. Thereby, reductions in the Industry and Power generation sector involve mainly sulfate aerosols, whereas Domestic and Traffic emission reductions impacts mostly black and organic carbon.

To disentangle the effects of changes in aerosol concentrations and GHG concentrations, we perform two additional sensitivity simulations: In one simulation $(A E)$, only aerosol and aerosol precursor emissions change, but GHG concentrations stay at the 2000 values. In a second simulation $(G H G)$, only the GHG concentrations change, whereas aerosol and aerosol precursor emissions stay at the 2000 level.

As mentioned in the previous section we use prescribed off-line oxidant concentrations for the sulfur chemistry scheme from prior TM3 simulations (Dentener et al. 2005), which applied the IIASA emission inventory for presentday (2000) and 2030 assuming a maximum feasible reduction of air pollutants. The $A E$ and $G H G+A E$ simulations use oxidant concentrations representative for the year 2030 (MFR case). All other simulations apply oxidant concentrations representative for the year 2000. On the global annual mean $\mathrm{O}_{3}, \mathrm{H}_{2} \mathrm{O}_{2}$, and $\mathrm{NO}_{2}$ burdens are reduced in the 2030 MFR case compared to 2000. In contrast, the $\mathrm{OH}$ burden is slightly higher. However, on a regional basis the trends vary considerably. A more detailed analysis of changes in the oxidant concentrations as well as the sensitivity of the aerosol abundance to these different oxidation concentrations is given in Kloster et al. (2008).

\subsubsection{Radiative forcing}

An uncoupled model version nudged to ERA40 2000 meteorology (Uppala et al. 2005) was applied in a previous 
model study (Kloster et al. 2008) estimating the GHG and aerosol RF associated with the simulations performed in this study. The perturbation of the present-day anthropogenic TOA RF is calculated as the difference between the perturbed future (2030) simulations minus the present day (2000) simulation. We note that our method of aerosol RF calculations does not strictly follow the definition of IPCC (Forster et al. 2007) since aerosol-cloud feedback mechanisms are enabled. We also diagnosed the atmospheric RF and surface RF. The surface RF is counterbalanced by heat and moisture fluxes at the surface level and is as such an indicator for potential changes in the hydrological cycle. The atmospheric RF equals the TOA total aerosol RF minus the surface RF. The resulting RFs are summarized in Table 2. We use the results presented in Kloster et al. (2008) to assess the climate sensitivity in this study.

\section{Results}

\subsection{Response of global and regional aerosol budget}

Table 3 summarizes the global annual mean changes in aerosol emissions, aerosol burdens and aerosol optical depth (AOD) for the single simulations. Interactively calculated aerosol and aerosol precursor emissions (DMS, sea salt and dust) respond to changes in the climate state. In all simulations we simulate an increase in the global annual mean surface temperature compared to the CONTROL simulation (see Sect. 3.2). Dust emissions increase in the GHG simulation $(+2 \%)$, while they decrease in all other simulations $(-3$ to $-7 \%)$. Strongest changes are simulated over North Africa related to changes in precipitation and soil moisture. However, due to the strong inter-annual variability of dust emissions, only a few regions show statistically significant changes. Global mean changes in sea salt emissions are very small $(+1$ to $+3 \%)$ in all simulations. Regionally, they increase in the high latitude regions in all simulations as a result of a sea-ice retreat in response to global warming. For the same reason, DMS emissions are increasing in all simulations $(+3$ to $+5 \%)$.

Prescribed anthropogenic $\mathrm{SO}_{2}, \mathrm{BC}$ and POM emissions are highest in the $G H G$ simulation, which assumes presentday aerosol emissions. In contrast, they are strongly reduced globally in the $A E$ and $G H G+A E$ simulations $\left(\mathrm{SO}_{2}\right.$ : $-59 \%$; $\mathrm{BC}:-28 \%$ and POM: $\left.-13 \%\right)$ in which aerosol emissions are reduced to a maximum technical feasible extent according to IIASA MFR 2030. Reduction are strongest over the anthropogenic source regions (e.g. South Asia: $\mathrm{SO}_{2}$ : $-56 \%$; BC: $-43 \%$; POM: $-46 \%$; Europe: $\mathrm{SO}_{2}$ : $-49 \%$; $\mathrm{BC}$ : $-70 \%$; POM: $-25 \%$; USA: $\mathrm{SO}_{2}$ : $-83 \%$; $\mathrm{BC}:-52 \%$; POM: $-9 \%$ ). The relative reductions for $\mathrm{BC}$ and $\mathrm{POM}$ are smaller than the one for $\mathrm{SO}_{2}$, as carbonaceous aerosols have substantial biomass burning sources, which are assumed in this study to remain constant in the future.

In the $G H G+D T$ simulation aerosol emissions are reduced globally, particularly for carbonaceous emissions (BC: $-23 \%$; POM: $-12 \%$ ), reflecting large emissions of carbonaceous aerosols from the Domestic and Transport sector. In contrast, anthropogenic $\mathrm{SO}_{2}$ emissions are only slightly reduced on the global annual mean $(-7 \%)$, mainly due to strong reduction over Europe $(-38 \%)$ and USA $(-9 \%)$, whereas they are still increasing over South Asia $(+176 \%)$. The GHG+IP simulation features strong reduction in anthropogenic $\mathrm{SO}_{2}$ emissions $(-47 \%)$ as the Industry and Powerplant sector are the dominant source sectors for anthropogenic $\mathrm{SO}_{2}$ emission. $\mathrm{BC}$ and $\mathrm{POM}$ emissions in the GHG+IP simulation are also reduced, but to a much lesser extent than in $G H G+D T$ (BC: $-17 \%$; POM: $-9 \%$ ).

The changes of the aerosol burdens and the AOD are displayed as annual zonal means in Fig. 1a-f. The burdens do not respond linearly to the emission changes as reflected in altered aerosol lifetimes (Table 4). The aerosol lifetime (defined as the ratio of global mean burden to global mean emission) is influenced by changes in the aerosol source distribution, aerosol composition, and deposition strengths

Table 2 Total sky top-of-the-atmosphere (TOA), surface and atmosphere net (shortwave plus longwave) radiative forcing (RF) in $\mathrm{W} \mathrm{m}^{-2}$ as simulated in Kloster et al. (2008)

\begin{tabular}{|c|c|c|c|c|c|c|c|c|c|}
\hline & \multicolumn{3}{|l|}{ TOA } & \multicolumn{3}{|l|}{ Surface } & \multicolumn{3}{|c|}{ Atmosphere } \\
\hline & Global & $\mathrm{NH}$ & $\mathrm{SH}$ & Global & $\mathrm{NH}$ & $\mathrm{SH}$ & Global & $\mathrm{NH}$ & $\mathrm{SH}$ \\
\hline$G H G+A E$ & 2.66 & 3.30 & 2.03 & 2.21 & 2.99 & 1.45 & 0.45 & 0.31 & 0.58 \\
\hline$G H G+D T$ & 1.71 & 1.82 & 1.58 & 1.10 & 1.27 & 0.95 & 0.60 & 0.55 & 0.63 \\
\hline$G H G+I P$ & 2.24 & 2.70 & 1.79 & 1.64 & 2.07 & 1.22 & 0.61 & 0.63 & 0.58 \\
\hline$G H G$ & 1.53 & 1.53 & 1.54 & 0.84 & 0.81 & 0.88 & 0.69 & 0.72 & 0.66 \\
\hline$A E$ & 1.13 & 1.77 & 0.49 & 1.37 & 2.18 & 0.57 & -0.24 & -0.41 & -0.08 \\
\hline
\end{tabular}

$\mathrm{RF}$ is here defined as the difference between the perturbed future simulations minus the present day (2000) simulation. Atmospheric RF is calculated as the difference in net radiation between TOA and surface 
Table 3 Global annual mean response (simulation minus CONTROL) for aerosol sources, burdens and aerosol optical depth (AOD)

\begin{tabular}{|c|c|c|c|c|c|c|}
\hline & & $\Delta G H G$ & $\triangle A E$ & $\Delta G H G+A E$ & $\Delta G H G+D T$ & $\Delta G H G+I P$ \\
\hline \multicolumn{7}{|l|}{ Source } \\
\hline $\mathrm{SO}_{2}$ & ( $\mathrm{Tg}[\mathrm{S}] /$ year) & $0.00(0)$ & $-41.62(-59)$ & $-41.62(-59)$ & $-4.92(-7)$ & $-33.21(-47)$ \\
\hline $\mathrm{SO}_{4}$ & (Tg[S]/year) & $0.55(+1)$ & $-27.81(-39)$ & $-27.23(-39)$ & $-1.33(-2)$ & $-21.61(-31)$ \\
\hline $\mathrm{BC}$ & (Tg/year) & $0.00(0)$ & $-2.25(-28)$ & $-2.25(-28)$ & $-1.9(-23)$ & $-1.4(-17)$ \\
\hline POM & (Tg/year) & $0.00(0)$ & $-8.78(-13)$ & $-8.78(-13)$ & $-8.53(-12)$ & $-6.44(-9)$ \\
\hline DMS & (Tg/year) & $0.66(+3)$ & $0.53(+2)$ & $1.35(+5)$ & $0.69(+3)$ & $1.08(+4)$ \\
\hline Dust & (Tg/year) & $13.76(+2)$ & $-44.83(-6)$ & $-53.01(-7)$ & $-20.55(-3)$ & $-50.42(-7)$ \\
\hline Sea salt & (Tg/year) & $7.89(0)$ & $2.03(0)$ & $17.62(0)$ & $4.88(0)$ & $-10.92(0)$ \\
\hline \multicolumn{7}{|l|}{ Burden } \\
\hline $\mathrm{SO}_{2}$ & $(\mathrm{Tg}[\mathrm{S}])$ & $-0.02(-2)$ & $-0.49(-45)$ & $-0.49(-44)$ & $-0.04(-4)$ & $-0.41(-38)$ \\
\hline Sulfate & $(\operatorname{Tg}[\mathrm{S}])$ & $0.03(+4)$ & $-0.28(-35)$ & $-0.26(-32)$ & $0.04(+5)$ & $-0.2(-25)$ \\
\hline $\mathrm{BC}$ & $(\mathrm{Tg})$ & $0.01(+6)$ & $-0.02(-17)$ & $-0.01(-13)$ & $-0.01(-12)$ & $0.00(-3)$ \\
\hline POM & $(\mathrm{Tg})$ & $0.06(+6)$ & $-0.07(-7)$ & $-0.01(-1)$ & $-0.04(-4)$ & $0.01(1)$ \\
\hline Dust & $(\mathrm{Tg})$ & $0.58(+7)$ & $-0.57(-7)$ & $-0.05(-1)$ & $-0.05(-1)$ & $-0.28(-3)$ \\
\hline Sea salt & $(\mathrm{Tg})$ & $0.21(+2)$ & $0.11(+1)$ & $0.41(+3)$ & $0.23(+2)$ & $0.30(+2)$ \\
\hline AOD & $* 100$ & $0.67(+4)$ & $-2.27(-14)$ & $-1.66(-10)$ & $0.39(+2)$ & $-1.26(-8)$ \\
\hline
\end{tabular}

Number in brackets denote percentage changes relative to the CONTROL simulation. For $\mathrm{SO}_{4}$ the source is the sum of $\mathrm{SO}_{2}$ in-cloud oxidation, condensation of gas-phase sulfuric acid, primary emissions, and nucleation

(dry deposition, wet deposition and sedimentation), which in turn are dependent on changes in climate.

One of the main impacts of changing aerosol composition is reflected in the altered aging times of BC and POM. The aging time can be determined by the ratio of the burden of the hydrophobic aerosol compounds divided by the rate, with which hydrophobic aerosols are transformed to hydrophilic aerosols. In ECHAM5-HAM, particles in the hydrophobic modes are transformed to the corresponding hydrophilic modes by condensation of sulfate on the particle surface or by coagulation with particles of the hydrophilic modes. The total condensable sulfate and the sulfate added by coagulation are attributed to the number of particles that can be coated with a minimal layer of sulfate in the respective mode. As minimal layer thickness a mono-layer is assumed (Stier et al. 2005). As already shown in a previous model study (Kloster et al. 2008), using identical aerosol and aerosol-precursor emissions as employed here, the aging time of $\mathrm{BC}$ and to a lesser extent of POM increases significantly in the MFR 2030 scenarios ( $A E$ and $G H G+A E$ simulation) compared to the CONTROL simulation (Table 4). This is caused by reduced $\mathrm{SO}_{2}$ emissions compared to the CONTROL simulation reducing the condensation of sulfuric acid on pre-existing aerosol particles and thus decreasing the transfer of aerosols from hydrophobic to hydrophilic modes. This becomes especially obvious in the $G H G+I P$ simulation, where preferentially $\mathrm{SO}_{2}$ emissions are reduced. The aging time of $\mathrm{BC}$ and POM increases by $33 \%$ and $15 \%$, respectively.
Aerosol lifetimes are also influenced by the climate state of the system. This can be inferred from the difference of the $G H G$ and the CONTROL simulation, which exhibit identical aerosol source strengths but different climate states (differences of e.g. $+1.2 \mathrm{~K}$ for global annual mean temperature and $+0.07 \mathrm{~mm} /$ day for precipitation (see also Table 5)). All aerosol compounds show a higher burden in the warmer $G H G$ simulation compared to the CONTROL simulation (e.g. $\mathrm{SO}_{4}$ : $+4 \%$; $\mathrm{BC}$ : $+6 \%$; POM: $+6 \%$ ) going along with an increase in their lifetimes (Tables 3, 4).

The largest enhancements in $\mathrm{SO}_{4}, \mathrm{BC}$ and POM burdens are simulated over the anthropogenic source regions in response to the globally warmer climate (Fig. 1a-c). For the $\mathrm{SO}_{4}$ burden this can be partly explained by an increase in the sulfate production rate $(+1 \%$, Table 3$)$. However, more importantly the increase in aerosol burden is controlled by changes in the deposition strengths with wet deposition being the dominant removal process on the global scale.

In the GHG simulation reduced deposition rates are simulated over regions with high aerosol emissions such as Southern Europe, USA, South Africa and South America leading to an increase in aerosol burdens and AOD (see Fig. 2a-d). Increasing deposition rates are simulated over the North Atlantic and in some equatorial regions. Changes in the deposition rate match to a large extent the precipitation response pattern (see Fig. 2e). Discrepancies are found over South Asia, where in large parts precipitation increases (see Fig. 2d), but deposition shows a decreasing 

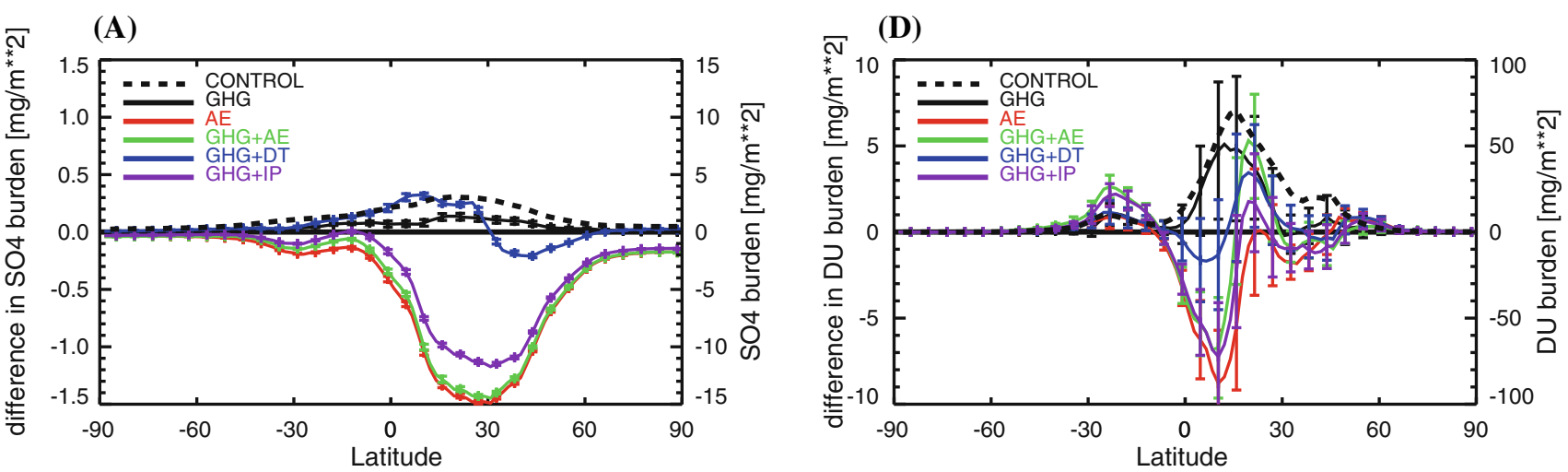

(B)
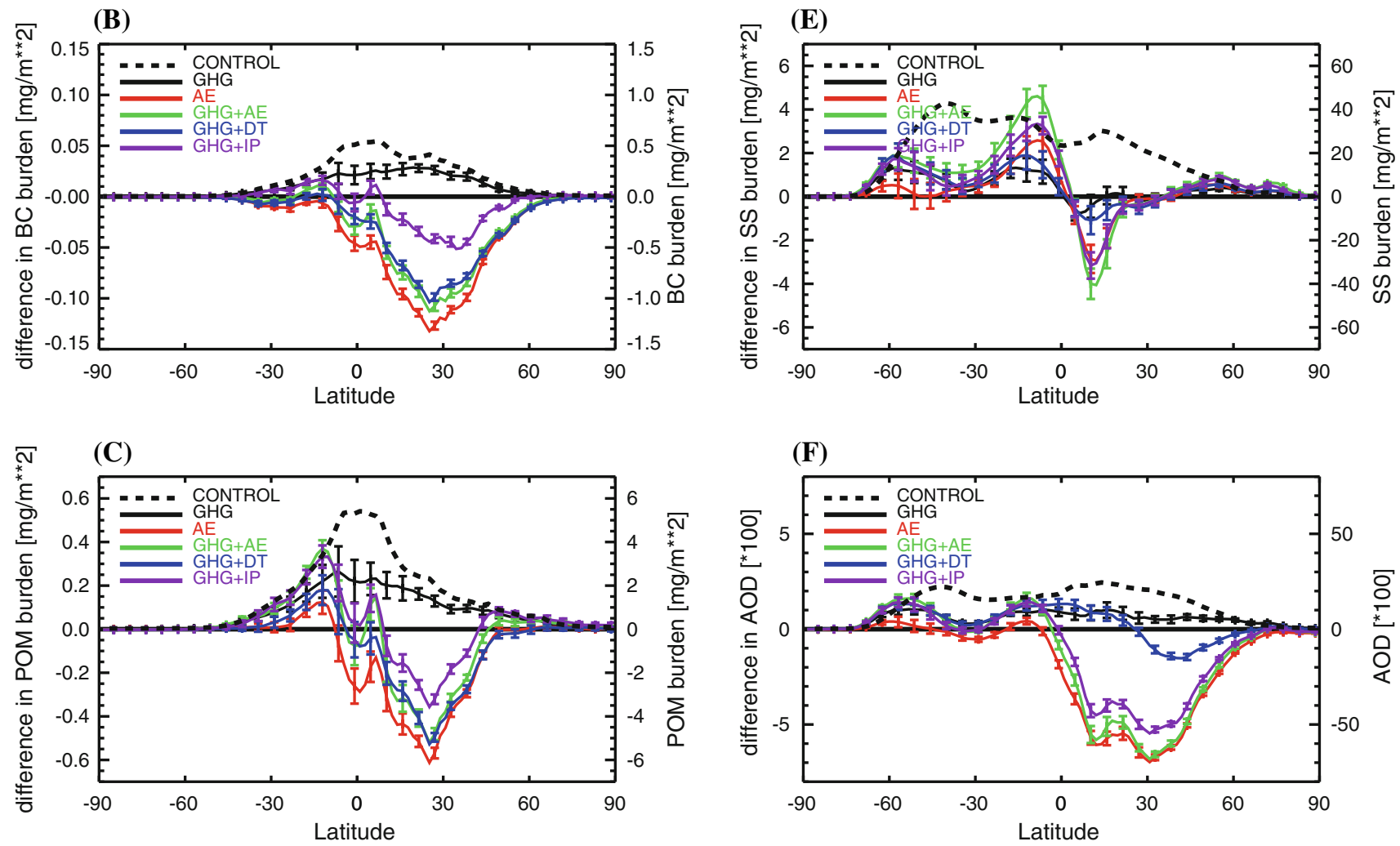

Fig. 1 Annual zonal mean changes in the aerosol burdens as simulated for the different simulations relative to the CONTROL simulation (EXP-CONTROL). The dashed lines represent absolute zonal mean values as simulated in the CONTROL simulation. For the

trend. However, changes in wet deposition are not linearly related to precipitation changes. Also precipitation frequency might be an important factor. Over South Asia we find a general trend of decreasing numbers of wet days (defined as the number of days with the precipitation exceeding $1 \mathrm{~mm}$ (ECA\&D, http://eca.knmi.nl/), see Fig. 2c,e), despite increasing precipitation. This leads to an increase in precipitation intensity (total precipitation divided by number of wet days), a feature simulated in most global climate model warming simulations (e.g. Meehl et al. 2007; Sun et al. 2007). A decrease in rain events although associated with heavier rain fall might explain the

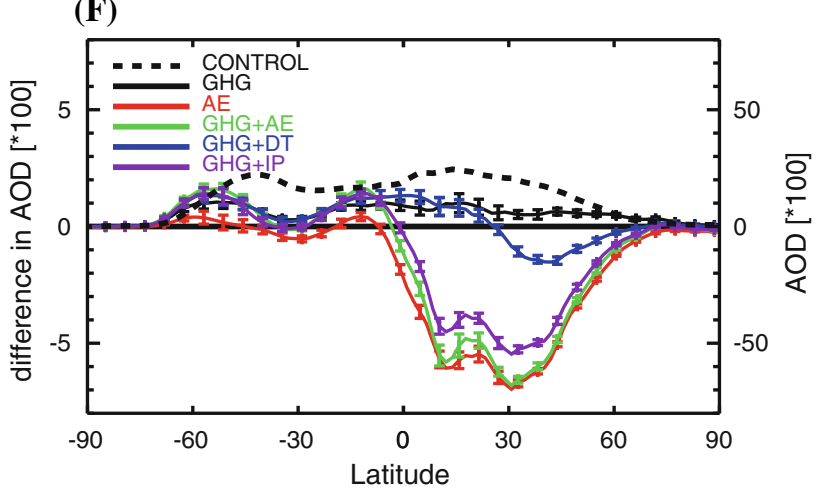

absolute values, please refer to the right axis. Error-bars represent 95\% confidence intervals (every third error bar is plotted). a Burden $\mathrm{SO}_{4}$, b Burden BC, c Burden POM, d Burden dust, e Burden Seasalt, and $\mathbf{f} \mathrm{AOD}$

simulated trend in decreasing deposition governed mainly by wet deposition over South Asia.

Recent GCM studies on the influence of the climate state on atmospheric aerosol concentrations have found different results. Unger et al. (2006) find an increase in surface sulfate concentrations over North Africa in a warmer climate $\left(0.68^{\circ} \mathrm{C}\right.$ warming between the 1990 s and 2030s) driven by higher sulfate production rates, which is consistent with our findings. However, on the global annual mean, they find a slightly decreasing $(<1 \%)$ sulfate burden by 2030 for the same MFR scenario as considered here, due to increasing wet deposition rates over China and the 
Table 4 Global annual mean response (simulation minus CONTROL) for aerosol lifetime and aging time

\begin{tabular}{|c|c|c|c|c|c|c|}
\hline & & $\Delta G H G$ & $\triangle A E$ & $\Delta G H G+A E$ & $\Delta G H G+D T$ & $\Delta G H G+I P$ \\
\hline \multicolumn{7}{|l|}{ Lifetime } \\
\hline $\mathrm{SO}_{2}$ & (d) & $-0.11(-3)$ & $-0.13(-3)$ & $-0.16(-4)$ & $0.04(+1)$ & $-0.26(-7)$ \\
\hline Sulfate & (d) & $0.12(+3)$ & $0.30(+7)$ & $0.42(+9)$ & $0.29(+6)$ & $0.35(+8)$ \\
\hline $\mathrm{BC}$ & (d) & $0.31(+6)$ & $0.78(+13)$ & $1.10(+17)$ & $0.77(+13)$ & $0.89(+15)$ \\
\hline POM & (d) & $0.31(+5)$ & $0.39(+7)$ & $0.70(+11)$ & $0.53(+9)$ & $0.61(10)$ \\
\hline DMS & (d) & $0.06(+4)$ & $0.06(+4)$ & $0.12(+7)$ & $0.10(+6)$ & $0.10(+6)$ \\
\hline Dust & (d) & $0.21(+5)$ & $-0.02(+0)$ & $0.31(+7)$ & $0.22(+5)$ & $0.17(+4)$ \\
\hline Sea salt & (d) & $0.01(+2)$ & $0.00(+1)$ & $0.02(+3)$ & $0.01(+2)$ & $0.02(+3)$ \\
\hline \multicolumn{7}{|c|}{ Aging time } \\
\hline $\mathrm{BC}$ & (d) & $0.02(+2)$ & $0.36(+44)$ & $0.35(+46)$ & $0.11(+13)$ & $0.26(+33)$ \\
\hline POM & (d) & $0.03(+2)$ & $0.26(+17)$ & $0.23(+18)$ & $0.00(0)$ & $0.21(+15)$ \\
\hline Dust & (d) & $0.25(+6)$ & $1.95(+46)$ & $1.89(+48)$ & $0.69(+17)$ & $1.39(+34)$ \\
\hline
\end{tabular}

Number in brackets denote percentage changes relative to the CONTROL simulation. Aging time is defined as the ratio of the burden of the hydrophobic aerosol compounds divided by the rate with which hydrophobic aerosols are transfered to hydrophilic aerosols

Table 5 Global annual mean temperature, precipitation and cloud response (simulation minus CONTROL).

\begin{tabular}{|c|c|c|c|c|c|c|}
\hline & & $\Delta G H G$ & $\triangle A E$ & $\Delta G H G+A E$ & $\Delta G H G+D T$ & $\Delta G H G+I P$ \\
\hline \multicolumn{7}{|l|}{ Global } \\
\hline Temperature & $(\mathrm{K})$ & $1.20(+8)$ & $0.96(+7)$ & $2.18(+15)$ & $1.39(+10)$ & $1.89(+13)$ \\
\hline Climate sensitivity & {$\left[\mathrm{K} /\left(\mathrm{W} \mathrm{m}^{-2}\right)\right]$} & 0.78 & 0.85 & 0.82 & 0.84 & 0.84 \\
\hline Precipitation & (mm/day) & $0.07(+2)$ & $0.08(+3)$ & $0.15(+5)$ & $0.08(+3)$ & $0.13(+4)$ \\
\hline Hydrological sensitivity & $(\% / \mathrm{K})$ & 1.96 & 2.81 & 2.36 & 1.86 & 2.24 \\
\hline Cloud cover & $(\%)$ & $-0.23(0)$ & $-0.52(-1)$ & $-1.00(-2)$ & $-0.45(-1)$ & $-0.78(-1)$ \\
\hline Cloud water path & $\left(\mathrm{g} \mathrm{m}^{-2}\right)$ & $1.76(+2)$ & $-2.57(-3)$ & $-1.33(-1)$ & $1.01(1)$ & $-0.20(0)$ \\
\hline Net surface SW & $\left(\mathrm{W} \mathrm{m} \mathrm{m}^{-2}\right)$ & $-0.40(0)$ & $1.32(+1)$ & $1.06(+1)$ & $-0.03(0)$ & $0.59(0)$ \\
\hline Net surface LW & $\left(\mathrm{W} \mathrm{m}^{-2}\right)$ & $2.02(-4)$ & $0.82(-1)$ & $2.76(-5)$ & $2.09(-4)$ & $2.53(-4)$ \\
\hline Latent heat flux & $\left(\mathrm{W} \mathrm{m}^{-2}\right)$ & $-2.00(+2)$ & $-2.28(+3)$ & $-4.36(+5)$ & $-2.45(+3)$ & $-3.59(+4)$ \\
\hline Sensible heat flux & $\left(\mathrm{W} \mathrm{m}^{-2}\right)$ & $0.55(-3)$ & $0.27(-1)$ & $0.81(-4)$ & $0.61(-3)$ & $0.72(-4)$ \\
\hline Total cloud forcing & $\left(\mathrm{W} \mathrm{m}{ }^{-2}\right)$ & $-0.04(0)$ & $0.64(-3)$ & $0.67(-3)$ & $0.15(-1)$ & $0.39(-2)$ \\
\hline
\end{tabular}

Number in brackets denote percentage changes relative to the CONTROL simulation. Outgoing fluxes have negative sign in ECHAM5. Climate sensitivity is defined as the ratio of global annual mean temperature change to the global annual mean top-of-the-atmosphere (TOA) radiative forcing. Hydrological sensitivity is defined analog to Boer (1993) as the ratio of global annual mean precipitation change in percentage to global annual mean temperature response. Note, that the cloud water path is the vertical integral of the liquid and ice water content

Southern Ocean. In accordance with our findings, Rae et al. (2007) find an increase in sulphate burden caused by a global warmer climate (present day compared to 2090) by approximately $9 \%$, which they attribute to reduced precipitation in regions with high sulphate abundance. Feichter et al. (2004) using a previous version of the model employed in this study, find a lower aerosol load in a warmer climate state $\left(0.57^{\circ} \mathrm{C}\right.$ warming due to increasing GHG concentrations and aerosol emissions from preindustrial to present-day times) compared to a relatively colder equilibrium climate simulation $\left(-0.87^{\circ} \mathrm{C}\right.$ cooling due to increasing aerosol emissions from pre-industrial to present-day times). They explain these findings by an enhanced hydrological cycle in a warmer climate. Also in contrast to our results, Liao et al. (2006) find decreasing aerosol burdens caused by a global warmer climate $\left(4.8^{\circ} \mathrm{C}\right.$ warming due to doubling of atmospheric $\mathrm{CO}_{2}$ concentration), mainly confined in the mid- and high-latitudes, caused by increasing wet-deposition rates. Changes are as high as a $-13 \%$ reduction for e.g. the $\mathrm{BC}$ burden on the global annual mean.

Overall, the relationship between precipitation change and deposition rate turns out to be highly non-linear, as it depends not only an the total precipitation amount, but also on precipitation frequency. Moreover, precipitation changes and aerosol concentrations are not independent, since 
(A)
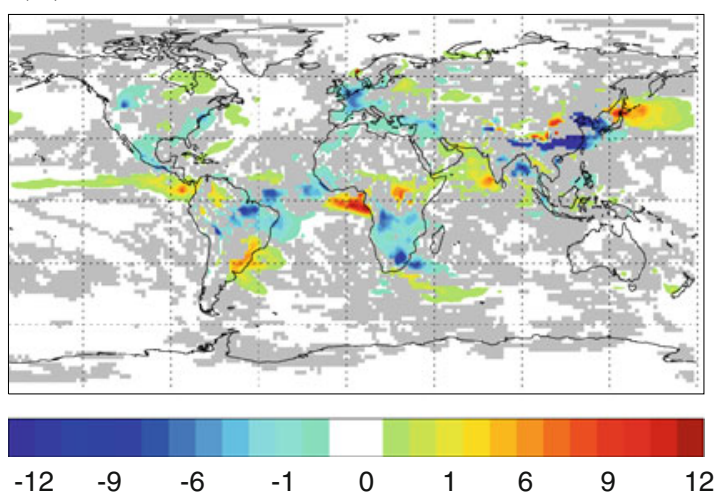

(B)

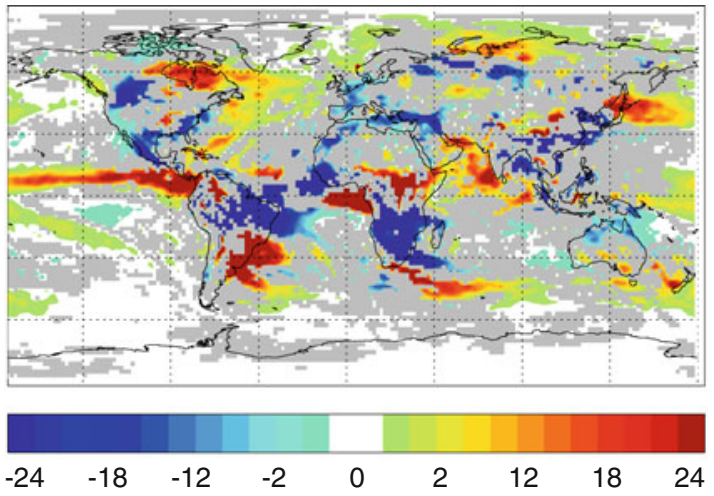

(C)
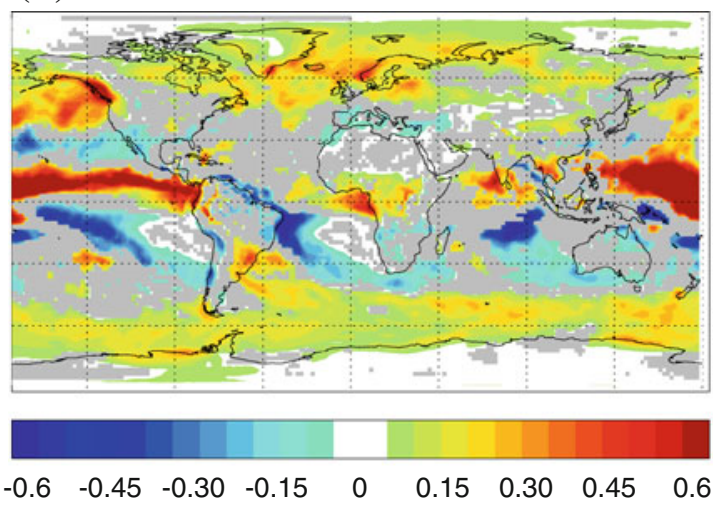

Fig. 2 Changes in the aerosol deposition strengths (sum of wet deposition, dry deposition and sedimentation) influenced by the climate state $(G H G-C O N T R O L)$ simulation in $\left[\mathrm{mg}\left(\mathrm{m}^{2} * \mathrm{~s}\right)^{-1}\right]$. Change in precipitation $(\mathrm{mm} /$ day), changes in the number of wet days defined as days with the precipitation exceeding $1 \mathrm{~mm}$ according to

aerosol concentrations affect cloud lifetimes (second indirect aerosol effect). In addition, results will strongly depend on the assumptions of future regional distributions of the aerosol emissions sources in combination with predicted regional changes in precipitation rate and intensity. More research is needed in order to be able to quantify the effect of climate change on aerosol concentrations in the
(D)

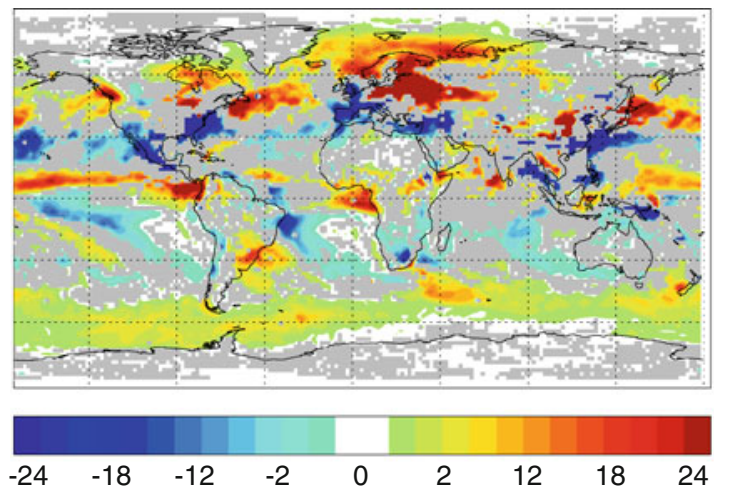

(E)

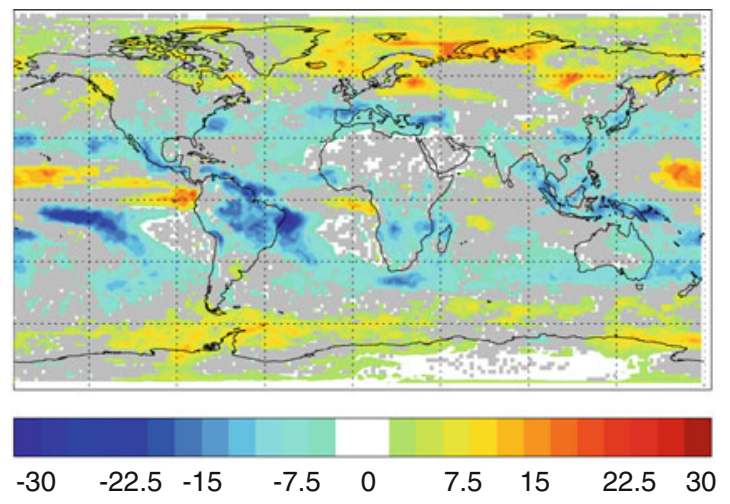

(F)

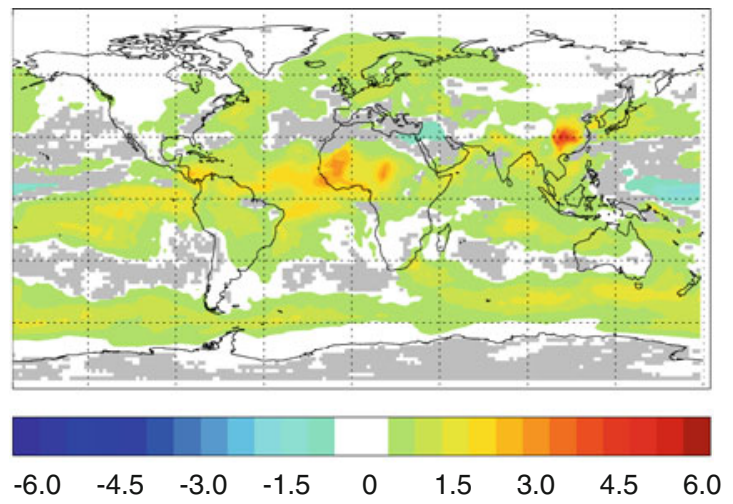

(ECA\&D, http://eca.knmi.nl/) and change in the aerosol optical depth (AOD) [*100]. Grey areas are regions where the changes are below the $5 \%$ significance level. a Deposition BC $\left[\mathrm{mg}\left(\mathrm{m}^{2} * \mathrm{~s}\right)^{-1}\right]$, b Deposition POM $\left[\mathrm{mg}\left(\mathrm{m}^{2} * \mathrm{~s}\right)^{-1}\right]$, c Precipitation [mm/day], d Deposition $\mathrm{SO}_{4}\left[\mathrm{mg}[\mathrm{S}]\left(\mathrm{m}^{2} * \mathrm{~s}\right)^{-1}\right]$, e Number of wet days [ ], and $\mathbf{f}$ AOD [ ]

atmosphere, especially as it is tightly connected to precipitation changes. Global climate models still differ widely in their ability to predict precipitation on the regional scale (Christensen et al. 2007). They also tend to overestimate observed precipitation trends over the last decades (Wentz et al. 2007). However, all of the studies mentioned above indicate that the impact of climate 
changes on atmospheric aerosol concentrations tends to be small, when compared to changes caused by a future maximum feasible mitigation of aerosol emissions.

\subsection{Temperature response and climate sensitivity}

The annual mean surface temperature as simulated in the CONTROL simulation and the response in the different simulations conducted are shown in Fig. 3a-f. The temperature increase in the $G H G$ simulation caused by

(A)
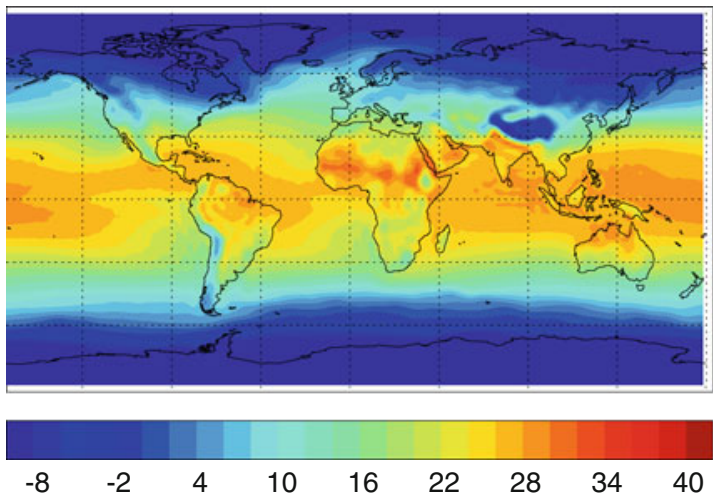

(B)
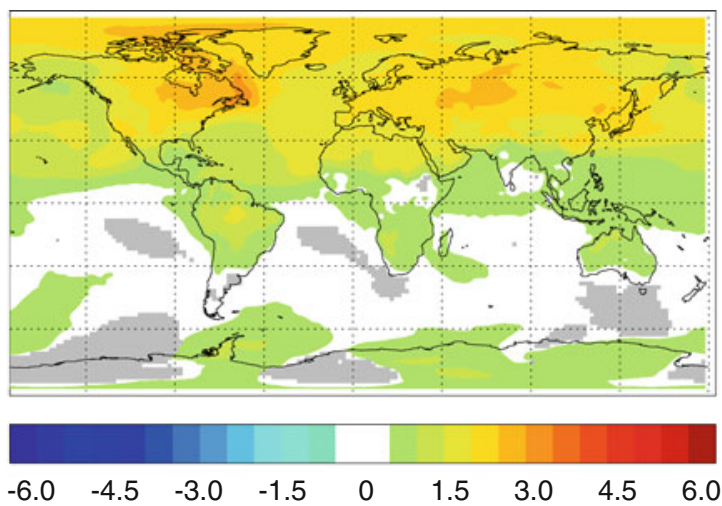

(C)
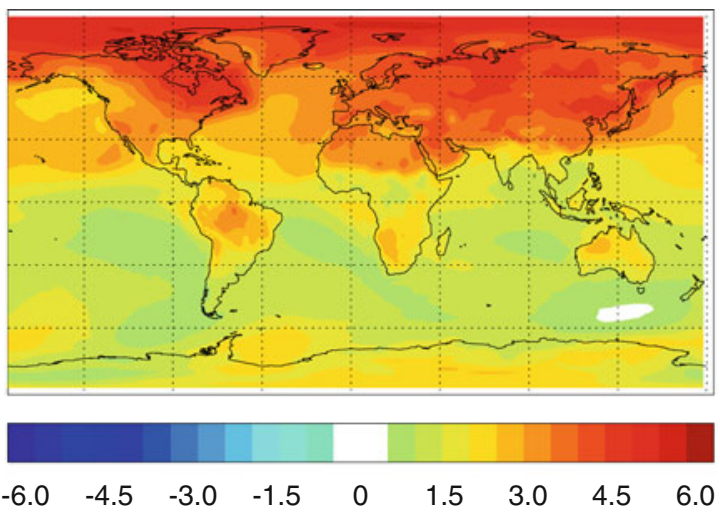

Fig. 3 Surface temperature as simulated in the CONTROL simulation (a) and the temperature response as simulated in the single simulations (b-f) in (K). Grey areas are regions where the changes increasing GHG concentrations amounts to $1.20 \mathrm{~K}$ on the global annual mean. In the $A E$ simulation the reduction in aerosol emissions leads to an increase in the global annual mean temperature by $0.96 \mathrm{~K}$. For the $G H G$ simulation the temperature increase is distributed more uniformly over the globe, although the temperature response is higher in the Northern Hemisphere partly caused by larger land coverage (NH: $1.46 \mathrm{~K}$; SH: $0.94 \mathrm{~K}$, giving a $\mathrm{NH}: \mathrm{SH}$ ratio of about 1.6). In contrast, the $A E$ simulation temperature increase is most pronounced in the Northern Hemisphere

(D)

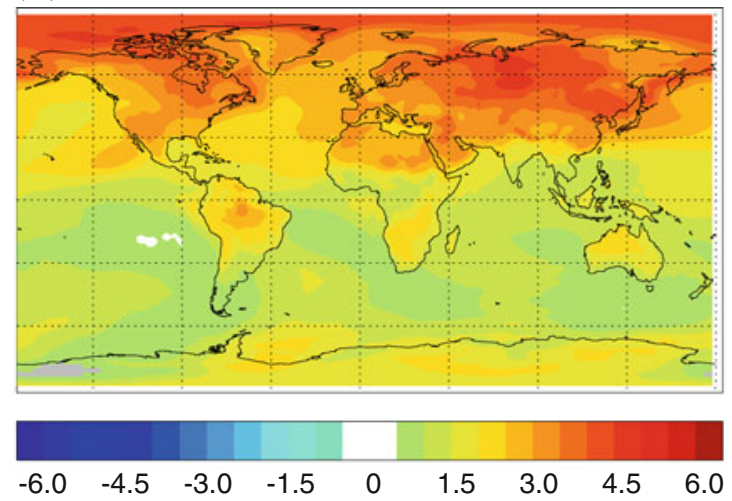

(E)

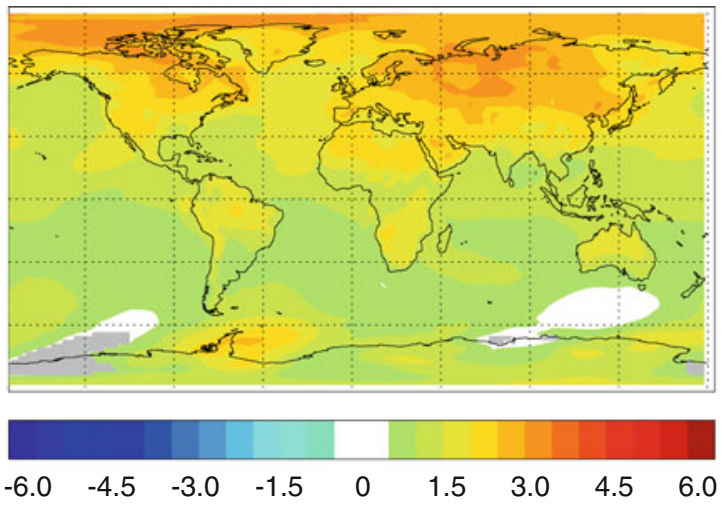

(F)

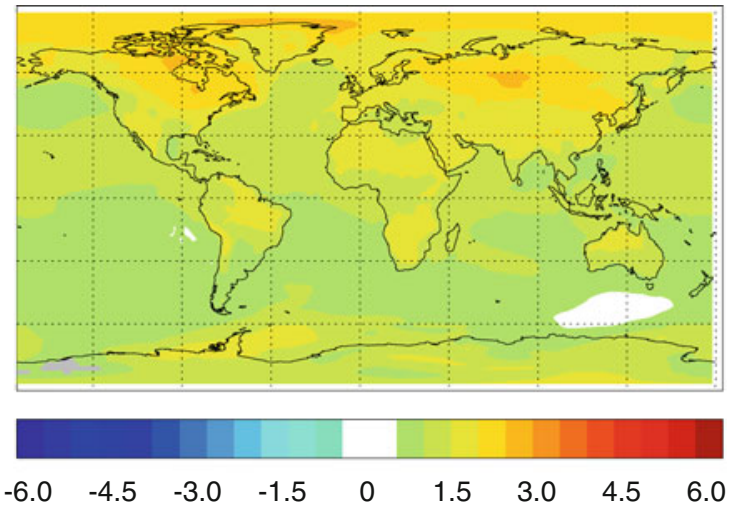

are below the $5 \%$ significance level. a CONTROL, b AE, c $\mathrm{GHG}+\mathrm{AE}, \mathbf{d} \mathrm{GHG}+\mathrm{IP}, \mathbf{e} \mathrm{GHG}+\mathrm{DT}$, and $\mathbf{f} \mathrm{GHG}$ 
facing high aerosol reductions (NH: $1.47 \mathrm{~K}$; SH: $0.44 \mathrm{~K}$, giving a NH:SH ratio of about 3.3). In the combined $G H G+A E$ simulation, the temperature increase is $2.18 \mathrm{~K}$, which is very similar to the sum of the single $G H G$ and $A E$ simulation (discussed further in Sect. 3.4). In case GHG concentrations increase and aerosols are reduced according to MFR 2030 only in the Domestic and Transport sector (simulation $G H G+D T$ ) the global mean temperature increases by $1.39 \mathrm{~K}(\mathrm{NH}: 1.81 \mathrm{~K}$; SH: $0.97 \mathrm{~K})$. In contrast, MFR 2030 applied in the Industry and Powerplant sector (simulation $G H G+I P$ ) leads to a temperature increase of $1.89 \mathrm{~K}(\mathrm{NH}: 2.56 \mathrm{~K}$; $\mathrm{SH}: 1.22 \mathrm{~K}$ ), which approximates the response for the $G H G+A E$ simulation, in which MFR 2030 is applied in all emission sectors. For all simulations, the largest changes occur in the polar regions in association with changes in snow and ice cover. Likewise in all simulations surface changes are largest over land surfaces compared to ocean surfaces, which is consistent with other global climate model studies (e.g. Meehl et al. 2007; Joshi et al. 2007).

Using results of Kloster et al. (2008), a comparison of the annual zonal mean radiative TOA forcing with the annual mean temperature response (Fig. 4a,b) shows immediately that the temperature response does not follow that of the RF pattern. All simulations including aerosol forcings show highest forcings over anthropogenic source regions with a maximum around $40^{\circ} \mathrm{N}$. However, the largest temperature response in all simulations is simulated in the Northern Hemisphere high latitudes. This agrees with previous GCM studies, which show that temperature response to RF is highest in the high latitude regions due to associated ice albedo feedbacks (Chung and Seinfeld 2005; Joshi et al. 2003; Boer and Yu 2003; Forster et al. 2000). Except for the high latitude regions, the temperature response due to aerosol forcing resembles to a large part the warming pattern caused by increasing GHG in the Northern Hemisphere (c.f. Fig. 3b, f). Thus, the response pattern is controlled to a large part by the regional climate response and not by regional radiative forcing pattern. This has also been demonstrated in previous GCM studies (Reader and Boer 1998; Levy-II et al. 2008; Shindell et al. 2008).

In the Northern Hemisphere the temperature response normalized by the global annual mean RF for the different simulations (Fig. 4c), reflecting the regional contributions to the global mean climate sensitivity, is larger in simulations including aerosol forcing compared to the simulation just considering GHG forcing. This enhanced response in the aerosol forcing experiments is caused by strong forcings over the Northern Hemisphere and is most pronounced in the high latitudes due to the ice-albedo feedback. For the Southern Hemisphere the temperature response normalized by the global annual mean RF is smaller in simulations
(A)

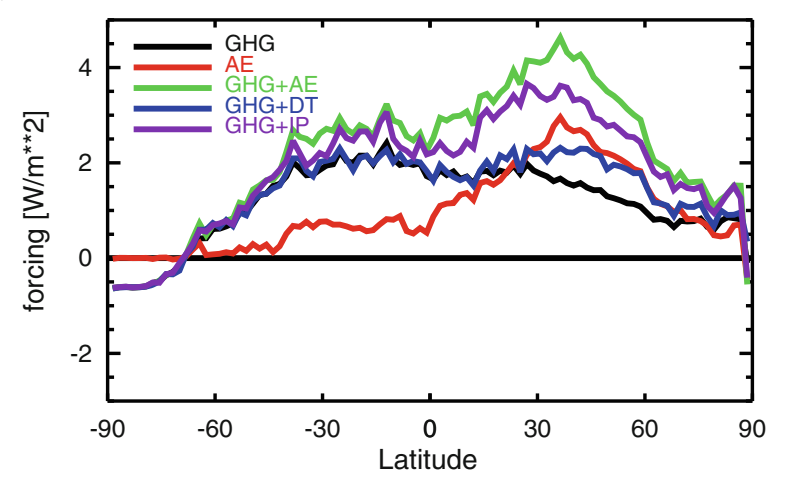

(B)

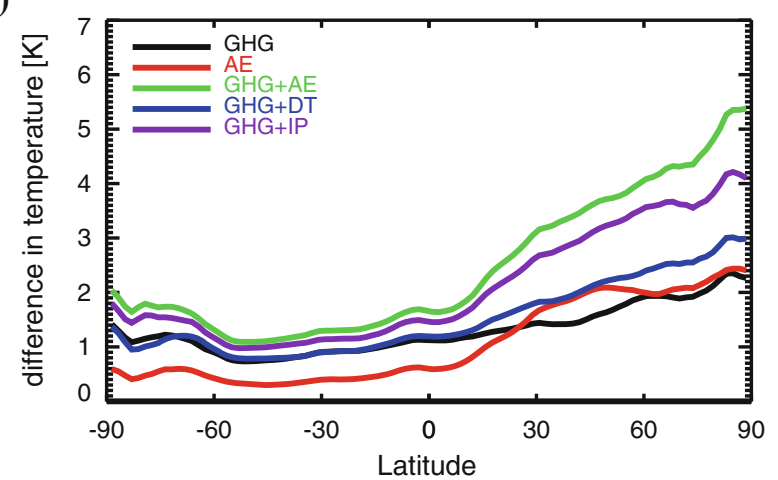

(C)

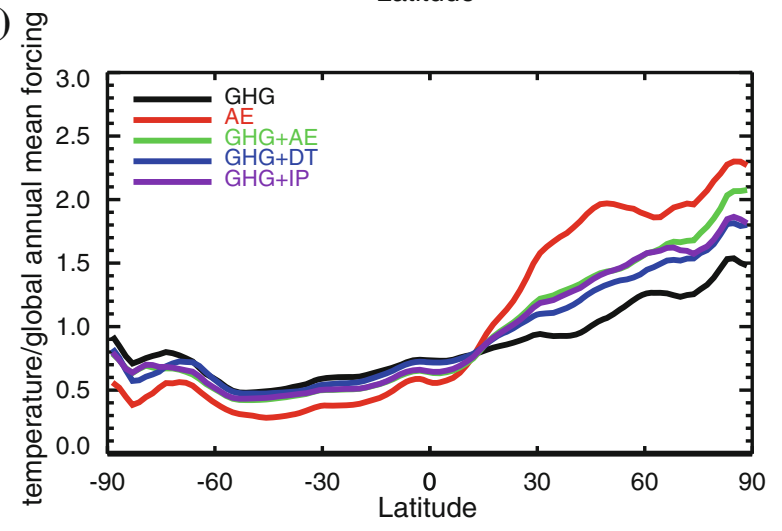

Fig. 4 Zonal annual mean for the different simulations. a Radiative forcing as simulated in Kloster et al. (2008) [W m $\left.{ }^{-2}\right]$. b Temperature response relative to CONTROL simulation (EXP-CONTROL) [K]. $\mathbf{c}$ Temperature response normalized by global annual mean radiative forcing $\left[\mathrm{K} /\left(\mathrm{W} \mathrm{m}^{-2}\right)\right]$

including aerosol forcing, although the differences are smaller as compared to the Northern Hemisphere. Consequently, the climate sensitivity, defined as the ratio of global annual mean temperature change to the global annual mean TOA RF, is lowest for the $G H G$ simulation $\left(0.78 \mathrm{~K} / \mathrm{W} \mathrm{m}^{-2}\right)$ and highest for the $A E$ simulation $\left(0.85 \mathrm{~K} / \mathrm{W} \mathrm{m}^{-2}\right.$, see Table 5). For reference, the $G H G$ climate sensitivity lies within the range of $0.67-1.37$ $\mathrm{K} / \mathrm{W} \mathrm{m}{ }^{-2}$ given for multi GCMs $2 \times \mathrm{CO}_{2}$ simulations (Randall et al. 2007; Meehl et al. 2007). 
(A)
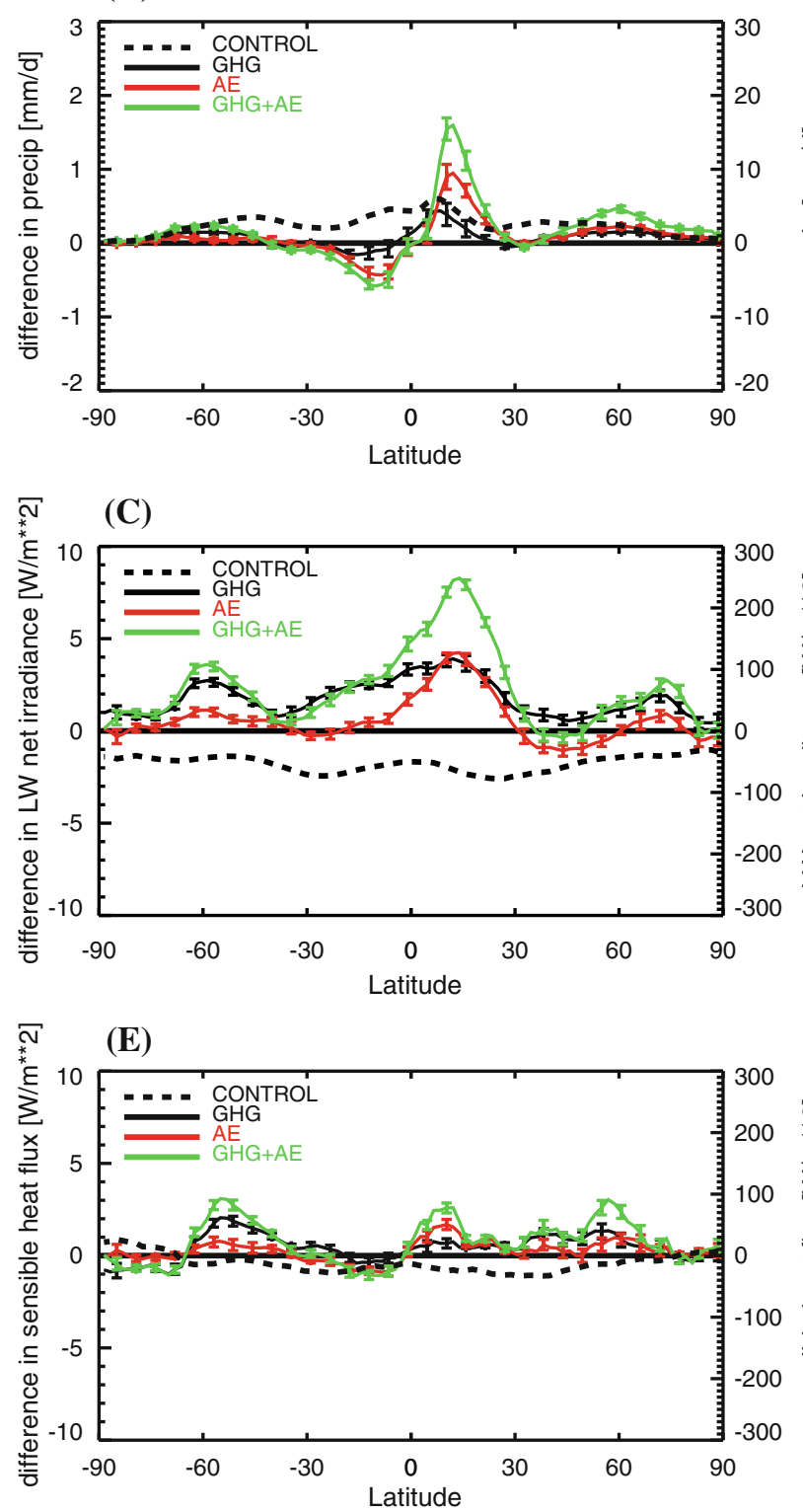

Fig. 5 Simulated changes in zonal annual (a) precipitation rate $(\mathrm{mm} /$ day), (b) evaporation (mm/day), (c) net surface long wave (LW) radiation $\left(\mathrm{W} \mathrm{m}^{-2}\right)$, (d) net surface short wave $(\mathrm{SW})$ radiation $\left(\mathrm{W} \mathrm{m}{ }^{-2}\right)$, (e) sensible heat flux $\left(\mathrm{W} \mathrm{m}^{-2}\right)$ and (f) latent heat flux $\left(\mathrm{W} \mathrm{m}{ }^{-2}\right.$ ). Upward fluxes have a negative sign in ECHAM5. The

\subsection{Hydrological cycle response and hydrological sensitivity}

Changes in the overall intensity of the hydrological cycle are controlled by the availability of energy at the surface (Allen and Ingram 2002). The surface energy balance requires that changes in downwelling radiation are balanced by changes in the loss of energy from the surface. This involves changes in longwave radiation emitted from the surface and latent and sensible heat fluxes (Boer 1993).
(B)
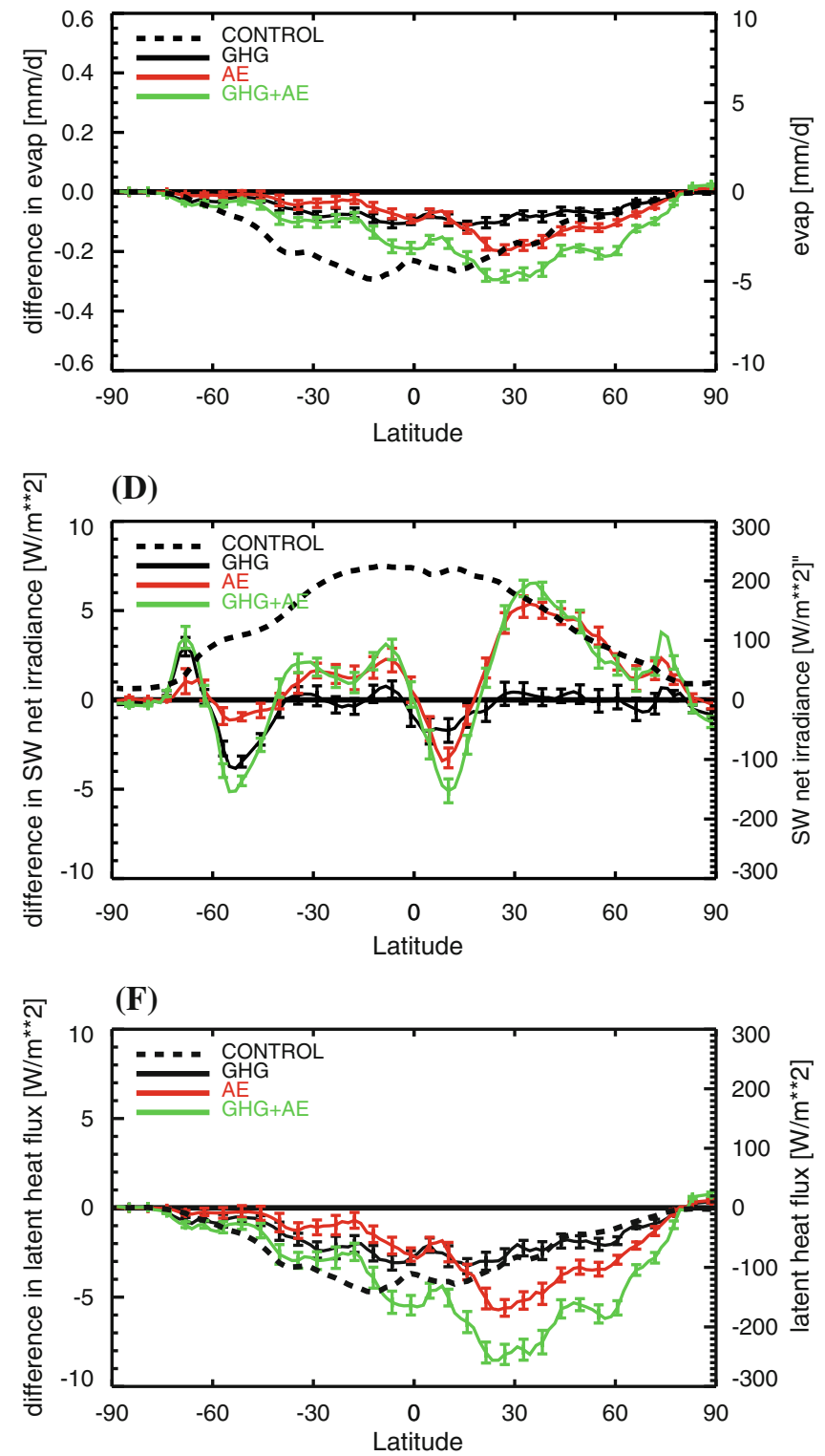

dashed lines represent absolute zonal mean values as simulated in the CONTROL simulation. For the absolute values, please refer to the right axis. Error-bars represent $95 \%$ confidence intervals (every third error bar is plotted)

The annual zonal mean precipitation and evaporation changes are displayed together with these changes (surface net solar and longwave radiation, latent and sensible heat flux) in Fig. 5a-f. In all simulations we find an increase in the global annual mean precipitation rate (see Table 5). Although the temperature response is simulated to be relatively smooth and with the same positive sign globally in all simulations, the precipitation response is much more spatially variable. The response pattern for precipitation is more complex as the precipitation response is governed by 
changes in surface evaporation, changes in the divergence of the water-vapour transport and changes in the divergence of the transport by transient eddies (Douville et al. 2002).

In all simulations an increase in precipitation in the tropics is simulated going along with smaller increases in mid-latitude regions and decreases in the sub-tropical subsidence regions. This kind of precipitation response to global warming is consistent with predictions of other global climate model simulations (e.g. Meehl et al. 2007). The tropical precipitation response pattern looks very similar in all simulations, despite that the response in simulations including aerosol forcings is enhanced and its maximum is shifted slightly northwards. This northward shift of the ITCZ due to decreasing aerosol emissions can be explained by a higher temperature gradient between the Northern and Southern Hemisphere caused by a stronger warming of the Northern Hemisphere (Rotstayn and Lohmann 2002). In all simulations we find clearly smaller changes in evaporation than in precipitation in lower latitudes so that the increase in equatorial regions is due to enhanced moisture convergence. For the adjacent areas moisture divergence prevails as a consequence of compensating subsidence.

In the $A E$ simulation precipitation changes in the Northern Hemisphere are larger compared to the $G H G$ simulation in regions with high aerosol forcings and subsequent strong increases in shortwave net surface radiation and latent heat flux, as over Asia, North Atlantic and North Pacific (Fig. 5a-c). In contrast, precipitation changes are smaller in the high latitudes of the Southern Hemisphere where aerosol forcing is low. In the global annual mean the $G H G$ simulation longwave net (downwelling minus upwelling, outgoing fluxes have a negative sign in ECHAM5) radiation at the surface increases by $2.02 \mathrm{~W} \mathrm{~m}^{-2}$, whereas the shortwave net surface radiation slightly decreases $\left(0.4 \mathrm{~W} \mathrm{~m}^{-2}\right)$. This is compensated globally by a decrease in sensible heat flux of $0.55 \mathrm{~W} \mathrm{~m}^{-2}$ and an increase in latent heat flux of $2.00 \mathrm{~W} \mathrm{~m}^{-2}$. Consequently, this leads to an increase in precipitation and evaporation of $0.7 \mathrm{~mm} /$ day $(+2 \%)$. In contrast the $A E$ simulation shows a distinct increase in shortwave net surface radiation $\left(1.32 \mathrm{~W} \mathrm{~m}^{-2}\right)$, which is compensated by an increase in longwave net surface radiation $\left(0.82 \mathrm{~W} \mathrm{~m}^{-2}\right)$, a slight decrease in sensible heat flux $\left(0.27 \mathrm{~W} \mathrm{~m}^{-2}\right)$ and an increase in latent heat flux of $2.28 \mathrm{~W} \mathrm{~m}^{-2}$. Consequently, this leads to an increase in precipitation and evaporation of $0.08 \mathrm{~mm} /$ day $(+3 \%)$. Thus, the stronger response of surface energy fluxes to aerosol forcings compared to GHG forcings results in a slightly stronger precipitation response.

The hydrological sensitivity, defined as the global precipitation change in percentage normalized by the temperature change, is $2.81 \% / \mathrm{K}$ in the $A E$ simulation compared to $1.96 \% / \mathrm{K}$ in the $G H G$ simulation (see Table 5). The combined $G H G+A E$ simulations results in a hydrological sensitivity of $2.36 \% / \mathrm{K}$, which is close to the temperature weighted average of the $A E$ and $G H G$ simulation (see Sect. 3.4 for further discussion). The simulation $G H G+I P$, in which the aerosol reduction is less compared to the $G H G+A E$ simulation, the hydrological sensitivity is lower $(2.24 \% / \mathrm{K})$. In contrast, the simulation $G H G+D T$ shows a hydrological sensitivity of $1.86 \% / \mathrm{K}$, which is even lower than that of the $G H G$ simulation. This reduction in hydrological sensitivity is partly caused by increasing $\mathrm{SO}_{2}$ emissions in the $G H G+D T$ simulations over large parts of South Asia, leading to reduced shortwave surface radiation when compared to the $G H G$ simulation despite decreasing $\mathrm{BC}$ and $\mathrm{POM}$ emissions while surface temperatures only show a weak response (see Fig. 3e, f). Overall, this reduces the latent heat flux and precipitation response and thus the hydrological sensitivity.

The hydrological sensitivity associated with increasing GHG forcing alone of $1.96 \% / \mathrm{K}$ agrees with previous modeling estimates (e.g. compilation of 15 CMIP2 models: 1.9\%/K; Le Treut and McAveney 2000). Higher hydrological sensitivities as a result of strong surface forcings caused by aerosols are found in previous studies, which investigates the effect of increasing aerosol emissions between pre-industrial and present day times (e.g. Liepert et al. 2004; Feichter et al. 2004; Allen and Ingram 2002). Increasing GHG concentrations in combination with increasing aerosol concentrations lead to the paradox, that global annual mean precipitation decreases, despite increasing temperatures. However, expected future air pollution mitigations, as considered in this study, will reverse this. Decreasing aerosol emissions in the future will lead to an even stronger increase in precipitation as can be expected from GHG forcing alone. Changes in cloud cover are small in all simulations $(<-2 \%$ see Table 5$)$. The global annual mean cloud cover is decreasing in simulations including aerosol forcing and remains unchanged in the $G H G$ simulation. The cloud water path (CWP, sum of liquid and ice water path) increases in the $G H G$ simulation $(+2 \%)$. In contrast, the $A E$ simulation shows a decreasing CWP $(-3 \%)$. This decrease in CWP likely results from the second indirect aerosol effect (reduction of cloud lifetime due to enhanced drizzle formation with decreasing aerosol concentrations) and leads together with a positive direct aerosol effect to an increase in solar net surface radiation.

\subsection{Additivity of the climate response}

GHGs and aerosols are fundamentally different in their nature as forcing agents. GHGs are relatively homogeneously distributed over the globe, whereas aerosols, 
with a lifetime on the order of a week, are concentrated in continental regions with strong anthropogenic sources. Despite these fundamental differences, the climate sensitivity of GHG forcing and aerosol forcings in our simulations are remarkably similar considering the range of uncertainties associated with the climate sensitivity itself (GHG: $0.78 \mathrm{~K} /\left(\mathrm{W} \mathrm{m}^{-2}\right)$; $A E: 0.85 \mathrm{~K} /\left(\mathrm{W} \mathrm{m}^{-2}\right)$ ). As discussed in Sect. 3.2, the larger climate sensitivity in the $A E$ simulation compared to the $G H G$ simulation is mainly driven by the strong forcing in the Northern Hemisphere leading to a larger temperature response caused by the icealbedo feedback in northern high latitude regions.

Similar climate sensitivities do not necessarily imply that the forcings and climate responses are additive. For example, the sum of the $G H G$ simulation in which only GHG concentrations are altered and the $A E$ simulation in which only aerosol emissions are altered does not necessarily equal the simulation in which both GHG concentrations and aerosol emissions are altered at the same time $(G H G+A E)$. Deviation from additivity can be expected as aerosols concentrations and thus aerosol forcings are not independent of the climate state. As shown for example in Sect. 3.1 aerosol concentrations are higher in a warmer climate due to changes in wet deposition rates. However, a comparison of the annual global mean temperature response given in Table 5 shows that in our simulation the response towards GHG and aerosol forcing is additive, the same holds for the globally integrated precipitation changes. Also, on the regional scale we do not find any significant deviations from additivity for temperature or precipitation response. An exception are the high latitude regions of the Northern Hemisphere in which the $G H G+A E$ simulation shows a higher temperature than the sum of the $A E$ and $G H G$ simulation, which is caused again by the ice-albedo feedback. More apparent deviations from additivity are simulated for the CWP, for which the response is $40 \%$ higher in the combined simulation compared to the sum of the two individual simulations. However, this deviation from additivity equals less than $1 \%$ of the total CWP, leading to even smaller deviations for the total cloud RF. This leads to the conclusion that for the given range of changes in GHG concentrations and aerosol emissions the climate impact can be simulated separately and added in order to get the overall climate response.

Note that recent studies have come to different conclusions. Feichter et al. (2004) found a considerable weaker global warming for combined GHG and aerosol forcings compared to the sum of the individual responses, driven by non-additive changes in the cloud water path and subsequently the cloud RF. Kirkevag et al. (2008) found on the global annual mean additive GHG and aerosol forcings in terms of temperature and precipitation response. Regionally, they find small deviations caused by positive cloud feedbacks associated with aerosol forcing. Gillett et al. (2004) investigated the additivity of $\mathrm{GHG}$ and $\mathrm{SO}_{4}$ direct aerosol forcing in a GCM without finding any deviations on the global or regional scale. Jones et al. (2007) found the sum of temperature and precipitation responses to changes in $\mathrm{BC}$, anthropogenic $\mathrm{SO}_{4}$ and biomass burning aerosols to be similar to an experiment in which all aerosols were changed simultaneously. All studies investigated changes between pre-industrial and present-day aerosol emissions, i.e. increasing aerosol emissions. In contrast, this study considers decreasing aerosol emissions, which are more likely to occur in the future as more and more regulations will be enforced to reduce health risks associated with aerosol particles.

\section{Conclusion}

This study uses the global atmospheric GCM aerosol model ECHAM5-HAM (Roeckner et al. 2003) coupled to a mixed layer ocean model to assess possible impacts of future aerosol and aerosol precursor emissions and GHG concentrations on climate. Equilibrium simulations are performed for present-day conditions and several combinations of GHG concentrations and aerosol emissions for the year 2030. Note, that we look at equilibrium responses for which the climate sensitivity is higher compared to a transient climate simulation as the ocean heat uptake delays the atmospheric warming (Meehl et al. 2007).

For aerosol emissions we investigate the extreme case of a maximum feasible abatement of aerosols in the near term future in combination with increasing GHG concentrations $(\mathrm{GHG}+\mathrm{AE})$, using an air pollution scenario recently developed by IIASA (Cofala et al. 2007) and SRES B2 GHG concentrations (IMAGE 2001). We conducted simulations in which only GHG concentrations are changed (GHG) or only aerosol emissions are changed (AE) to disentangle the importance of both individual forcing agents. By comparing the sum of these simulations to the simulation in which both forcing agents are changed simultaneously we get a measure of the additivity of GHG and aerosol forcings. We contrasted this with scenarios in which only the Industry and Powerplant sector $(\mathrm{GHG}+\mathrm{IP})$ or the Domestic and Transport sector $(\mathrm{GHG}+\mathrm{DT})$ apply a maximum feasible reduction strategy, whereas the other sectors follow current legislations (CLE).

The major results of this study are as follows:

1. An increase in GHG concentrations alone leads to an increase in the equilibrium temperature response of $1.20 \mathrm{~K}$. A maximum feasible reduction of aerosol and aerosol precursor emissions leads to $0.96 \mathrm{~K}$ higher 
temperatures, almost as high as the GHG effect reflecting the large potential of aerosols to impact climate. The response in the combined simulation $(G H G+A E)$ in which both agents are changed simultaneously equals the sum of the individual responses on a global and regional scale. The same additivity is found for precipitation. Slight deviations are simulated for the cloud water path and subsequently cloud RF $(<1 \%)$. Thus, in the context of the current simulations the climate response to aerosol and GHG forcings are additive. However, this result depends crucially on the aerosol emission scenario and strength of the GHG forcings applied, as aerosol abundance itself is a function of the climate state.

2. An increase in GHG concentrations in combination with a maximum feasible reduction of aerosol and aerosol precursor emissions by 2030 leads to an equilibrium temperature response of $2.18 \mathrm{~K}$ (aerosol emissions decrease by $-59 \%$ for $\mathrm{SO}_{2},-28 \%$ for $\mathrm{BC}$ and $-13 \%$ for $\mathrm{POM})$. A maximum feasible reduction of aerosol and aerosol precursor emissions only applied in the Industry and Powerplant sector (GHG + IP) leads to a temperature increase of $1.89 \mathrm{~K}$ (aerosol emissions decrease by $-47 \%$ for $\mathrm{SO}_{2},-17 \%$ for $\mathrm{BC}$ and $-9 \%$ for POM). In contrast, a maximum feasible reduction of aerosol and aerosol precursor emissions only applied in the Domestic and Transport sector (GHG + DT) leads to a smaller temperature increase of $1.39 \mathrm{~K}$ (aerosol emissions decrease by $-7 \%$ for $\mathrm{SO}_{2},-23 \%$ for $\mathrm{BC}$ and $-12 \%$ for POM). The climate sensistivities for the single simulations are: $\mathrm{GHG}+\mathrm{AE}: 0.82 \mathrm{~K} /\left(\mathrm{W} / \mathrm{m}^{2}\right) ; \mathrm{GHG}+\mathrm{IP}$ : $0.84 \mathrm{~K} /\left(\mathrm{W} / \mathrm{m}^{2}\right) ; \mathrm{GHG}+\mathrm{DT}: 0.84 \mathrm{~K} /\left(\mathrm{W} / \mathrm{m}^{2}\right)$.

3. The precipitation response and thus the hydrological sensitivity differs strongly for GHG forcing and aerosol forcings. As aerosol forcing strongly impacts surface fluxes, the response of latent heat flux and thus precipitation is stronger compared to GHG forcings (Liepert et al. 2004). We find a hydrological sensitivity for the GHG simulation of $1.96 \% / \mathrm{K}$ and $2.81 \% / \mathrm{K}$ for the $\mathrm{AE}$ simulation. As a result the precipitation increase is strongly enhanced when aerosol forcings are considered (e.g. GHG: $+0.07 \mathrm{~mm} / \mathrm{day}$; GHG + AE: $+0.15 \mathrm{~mm} /$ day, GHG + IP: $+0.13 \mathrm{~mm} /$ day, GHG + DT: +0.08 $\mathrm{mm} /$ day).

4. Aerosol abundance is not independent from the climate state as demonstrated in previous GCM studies (Unger et al. 2006; Feichter et al. 2004; Liao et al. 2006). Here we find enhanced aerosol burdens $\left(\mathrm{SO}_{4}:+4 \%\right.$, $\mathrm{BC}:+6 \%$, POM: $+6 \%$ ) in the warmer GHG simulation compared to the CONTROL simulation both using identical aerosol emissions. Burdens increase most pronounced over the anthropogenic source regions due to decreasing deposition rates. Thus our model results suggest that climate change alone would worsen the air pollution by aerosol. The changes in the aerosol abundance are largely driven by changes in wetdeposition. This in turn depends on precipitation changes for which global climate models still differ widely in their predictions on the regional scale (Christensen et al. 2007).

The above conclusions are all subject to the caveat that many aspects of aerosol climate interaction are uncertain and treated highly simplified in GCMs. Future climate change will also alter natural aerosol emissions such as DMS, sea salt, mineral dust and emissions by wildfires (Kloster et al. 2007; Mahowald et al. 2006a, b; Tegen et al. 2004). These changes are not considered in the current study.

The most robust conclusion from this study is that a maximum feasible reduction of anthropogenic aerosol emissions in the future will have a substantial warming effect. Most of the warming is caused by sulfur emission reductions in the Industry and Power generation sector. Emission reduction in the Domestic and Transport sector alone have less impact on climate, since these sectors emit less sulfur, and in addition the removal of absorbing carbonaceous aerosol may lead to a net cooling effect. When such a strong reduction will take place over the next decades (by 2030), warming caused by aerosol reduction can be almost as high as warming induced by increased GHG concentrations within the same time period. The reduction of aerosols will also lead to a significant increase in global mean precipitation.

The MFR assumption used in this study clearly results in an upper limit to the climate impact of air pollution. However, this assumption is probably not completely unrealistic, as for instance in Europe new regulations impose that air pollutant emissions are effectively abated to almost $70 \%$ of MFR. Furthermore, fuel shifts and energy savings may lead to additional emission reductions.

Our study has quantified a number of linkages that exist between climate change, aerosol pollution and between the policies to combat them. There are clearly co-benefits of climate change policies for reducing air pollution: structural changes in emission source sectors required for GHG emission reduction will also result in a reduction of air pollutant emissions (Swart et al. 2004). Our study highlights the drawbacks of air pollution reduction for fighting global warming, in particular caused by the additional warming due to reduced aerosol pollution. To avoid this additional warming is has to be an urgent priority to decrease anthropogenic GHG emissions in the near future, even to a greater extent than currently proposed. Therefore, climate change mitigation strategies should take into account the combined climate impacts caused by improved air quality and changes in GHG emissions. Vice versa, air pollution mitigation 
strategies, should consider the co-benefits of reductions via structural changes in the energy sector.

Acknowledgments The authors thank the German Computing Centre (DKRZ), the Swiss Computing Centre (CSCS) and the ECMWF for computing time and Z. Klimont, J. Cofala and M. Amann for the emission data. J. Feichter and I. Fischer-Bruns thank the SFB512 for support. This work was partly supported by NSF-0758369.

Open Access This article is distributed under the terms of the Creative Commons Attribution Noncommercial License which permits any noncommercial use, distribution, and reproduction in any medium, provided the original author(s) and source are credited.

\section{References}

Albrecht BA (1989) Aerosols, cloud microphysics, and fractional cloudiness. Science 245:1227-1230

Allen M, Ingram W (2002) Constraints on future changes in climate and the hydrological cycle. Nature 419:224-232

Boer G (1993) Climate change and the regulation of the surface moisture and energy budgets. Clim Dyn 8:225-239

Boer GJ, Yu B (2003) Climate sensitivity and response. Clim Dyn 20(4):415-429

Christensen J, Hewitson B, Busuioc A, Chen A, Gao X, Held I, Jones R, Kolli R, Kwon WT, Laprise R, Rueda VM, Mearns L, Menendez C, Raeisaenen J, Rinke A, Sarr A, Whetton P (2007) Regional climate projections. In: Solomon S, Wuin D, Manning M, Chen Z, Marquis M, Averyt K, Tignor M, Miller H (eds) Climate Change 2007: The Physical Science Basis. Contribution of working group I to the fourth assessment report on the Intergovernmental Panel on Climate Change, Cambridge University Press, Cambridge, United Kingdom and New York, NY, USA

Chung S, Seinfeld J (2005) Climate response of direct radiative forcing of anthropogenic black carbon. J Geophys Res 110:doi: 10.1029/2004JD005441

Cofala J, Amann M, Klimont Z, Kupiainen K, Hglund-Isaksson L (2007) Scenarios of global anthropogenic emissions of air pollutants and methane until 2030. Atmos Environ 41(38):84868499

Dentener F, Stevenson D, Cofala J, Mechler R, Amann M, Bergamaschi P, Raes F, Derwent R (2005) The impact of air pollutant and methane emissions controls on tropospheric ozone and radiative forcing: CTM calculations for the period 1990 2030. Atmos Chem Phys 5:1731-1755

Douville H, Chauvin F, Planton S, Royer JF, Salas-Melia D, Tyteca S (2002) Sensitivity of the hydrological cycle to increasing amounts of greenhouse gases and aerosols. Clim Dyn 20:doi: 10.1007/s00382-002-0259-3

Eyring V, Koehler H, Lauer A, Lemper B (2005) Emissions from international shipping: 2. impact of future technologies on scenarios until 2050. J Geophys Res 110:doi:10.1029/2004JD005620

Feichter J, Kjellstrom E, Rodhe H, Dentener F, Lelieveld J, Roelofs GJ (1996) Simulation of the tropospheric sulfur cycle in a global climate model. Atmos Environ 30(10-11):1693-1707

Feichter J, Roeckner E, Lohmann U, Liepert B (2004) Nonlinear aspects of the climate response to greenhouse gas and aerosol forcing. J Clim 17(12):2384-2398

Forster P, Blackburn M, Glover R, Shine K (2000) An examination of climate sensitivity for idealised climate change experiments in an intermediate general circulation model. Clim Dyn 16:833849

Forster P, Ramaswamy V, Artaxo P, Berntsen T, Betts R, Fahey D, Haywood J, Lean J, Lowe D, Myhre G, Nganga J, Prinn R, Raga G, Schulz M, Dorland RV (2007) Changes in atmospheric constituents and in radiative forcing. In: Solomon S, Wuin D, Manning M, Chen Z, Marquis M, Averyt K, Tignor M, Miller H (eds) Climate Change 2007: The Physical Science Basis. Contribution of working group I to the fourth assessment report on the Intergovernmental Panel on Climate Change, Cambridge University Press, Cambridge, United Kingdom and New York, NY, USA

Gillett NP, Wehner MF, Tett SFB, Weaver AJ (2004) Testing the linearity of the response to combined greenhouse gas and sulfate aerosol forcing. Geophys Res Lett 31(14):L14201

Hansen J, Sato M, Ruedy R (1997) Radiative forcing and climate response. J Geophys Res 106:6831-6864

Hansen J, Sato M, Ruedy R, Nazarenko L, Lacis A, an G Russel GS, Aleinov I, Bauer M, Bauer S, Bell N, Cairns B, Canuto V, Chandler M, Cheng Y, Genio AD, Faluvegi G, Fliming E, Friend A, Hall T, Jackman C, Kelly M, Kiang N, Koch D, Lean J, Lerner J, Lo K, MEnon S, Miller R, Minnis P, Novakov T, Oinas V, Perlwitz J, Perlwitz J, Rind D, Romanou A, Shindell D, Stone P, Sun S, Tausnev N, Tresher D, Wielicki B, Wong T, Yao M, Xhang Z (2005) Efficacy of climate forcings. J Geophys Res 110:doi:10.1029/2005JD005776

IMAGE (2001) The IMAGE 2.2 implementation of the SRES scenarios: a comprehensive analysis of emissions, climate change and impacts in the 21 st century. CD-ROM publication 481508018, RIVM, National Institute for Public Health and the Environment, Bilthoven, The Netherlands

IPCC (2001) Climate change 2001: The Scientific Basis. Cambridge University Press. J.T. Houghton, 881 pp

Jones A, Haywood JM, Boucher O (2007) Aerosol forcing, climate response and climate sensitivity in the Hadley Centre climate model. J Geophys Res 112:doi:10.1029/2007JD008688

Joshi M, Shine K, Ponater M, Stuber N, Sausen R, Li L (2003) A comparison of climate response to different radiative forcing in three general circulation models: towards and improved metric of climate change. Clim Dyn 20:843-854

Joshi M, Gregory J, Webb M, Sexton D, Johns T (2007) Mechanism for the land/sea warming contrast exhibited by simulations of climate change. Clim Dyn 30:doi:10.1007/s00382-007-0306-1

Kiehl JT, Schneider TL, Portmann RW, Solomon S (1999) Climate forcing due to tropospheric and stratospheric ozone. J Geophys Res 104(D24):31239-31254

Kirkevag A, Iversen T, Kristjansson J, Seland O, Debernard J (2008) On the additivity of climate response to anthropogenic aerosols and $\mathrm{CO}_{2}$, and the enhancement of future global warming by carbonaceous aerosols. Tellus A 60A:513-527

Kloster S, Six K, Feichter J, Maier-Reimer E, Roeckner E, Wetzel P, Stier P, Esch M (2007) Response of dimethylsulfide (DMS) in the ocean and atmosphere to global warming. J Geophys Res 112:doi:10.1029/2006JG000224

Kloster S, Dentener F, Feichter J, Raes F, van Aardenne J, Roeckner E, Lohmann U, Stier P, Swart R (2008) Influence of future air pollution mitigation strategies on total aerosol radiative forcing. Atmos Chem Phys 8:6405-6437

Le Treut H, McAveney B (2000) A model intercomparison of equilibrium climate change in response to $\mathrm{CO}_{2}$ doubling. Technical report 18, Institute Pierre Simon La Place, Paris

Levy-II H, Schwarzkopf MD, Horowitz L, Ramaswamy V, Findell K (2008) Strong sensitivity of late 21 st century climate to projected changes in short-lived air pollutants. J Geophys Res 113:doi: 10.1029/2007JD009176 
Liao H, Chen WT, Seinfeld J (2006) Role of climate change in global predictions of future tropospheric ozone and aerosols. J Geophys Res 111:doi:10.1029/2005JD006852

Liepert B, Feichter J, Lohmann U, Roeckner E (2004) Can aerosols spin down the water cycle in a warmer and moisture world? Geophys Res Lett 31:doi:10.1029/2003GL019060

Lin H, Leaitch R (1997) Development of an in-cloud aerosol activation parameterization for climate modelling. In: Proceedings of the WMO workshop on measurements of cloud properties for forcast of weather, Geneva, pp 328-335

Lohmann U, Stier P, Hoose C, Ferrachat S, Kloster S, Roeckner E, Zhang J (2007) Cloud microphysics and aerosol indirect effects in the global climate model ECHAM5-HAM. Atmos Chem Phys 7:3425-3446

Mahowald N, Lamarque JF, Tie X, Wolff E (2006a) Sea salt aerosol response to climate change: last glacial maximum, pre-industrial and doubled carbon dioxide climates. J Geophys Res 111:doi: 10.1029/2005JD006459

Mahowald N, Muhs D, Levis S, Rasch P, Yoshioka M, Zender C, Luo $\mathrm{C}$ (2006b) Change in atmospheric mineral aerosols in response to climate: last glacial period, preindustrial, modern, and doubled carbon dioxide climates. J Geophys Res 111:doi:10.1029/ 2005JD006653

Meehl G, Stocker T, Collins W, Friedlingstein P, Gaye A, Gregory J, Kitoh A, Knutti R, Noda JMA, Raper S, Watterson I, Weaver A, Zhao ZC (2007) Global climate projections. In: Solomon S, Wuin D, Manning M, Chen Z, Marquis M, Averyt K, Tignor M, Miller H (eds) Global Climate projections in Climate Change 2007: The Physical Science Basis. Contribution of working group I to the fourth assessment report on the Intergovernmental Panel on Climate Change, Cambridge University Press, Cambridge, United Kingdom and New York, NY, USA

Nakicenovic et al (2000) Special report on emissions scenarios. In: Contribution to the Intergovernmental Panel on Climate Change, Cambridge University Press, Cambridge, UK

Nazarenko L, Menon S (2005) Varying trends in surface energy fluxes and associated climate between 1960 and 2002 based on transient climate simulations. Geophys Res Lett 32:doi:10. 1029/2005GL024089

Olivier J, Berdowski J (2001) Global emission sources and sinks. In: The climate system. Swets and Zeitlinger Publishers, Lisse, The Netherlands

Rae JGL, Johnson CE, Bellouin N, Boucher O, Haywood JM, Jones A (2007) Sensitivity of global sulphate aerosol production to changes in oxidant concentrations and climate. J Geophys Res 112:doi:10.1029/2006JD007826

Randall D, Wood R, Bony S, Colman R, Fichefet T, Fyfe J, Kattsov V, Pitman A, Shukla J, Srinivasan J, Stouffer R, Sumi A, Taylor K (2007) Climate models and their evaluation. In: Solomon S, Wuin D, Manning M, Chen Z, Marquis M, Averyt K, Tignor M, Miller H (eds) Climate Change 2007: The Physical Science Basis. Contribution of working group I to the fourth assessment report on the Intergovernmental Panel on Climate Change. Cambridge University Press, Cambridge, United Kingdom and New York, NY, USA

Reader M, Boer G (1998) The modification of greenhouse gas warming by the direct effect of sulphate aerosols. Clim Dyn 14:593-607

Riahi K, Roehl R (2005) Greenhouse gas emissions in a dynamicsas-usual scenario of economic and energy development. Technol Forcast Soc Change 63:175-205

Roberts D, Jones A (2004) Climate sensitivity of black carbon aerosol from fossil fuel combustion. J Geophys Res 109:doi:10.1029/ 2004JD004676

Roeckner E, Siebert T, Feichter J (1995) Climatic response to anthropogenic sulfate forcing simulated with a general circulation model. In: Charlson R, Heintzenberg J (eds) Aerosol forcing of climate. Wiley, pp 349-362

Roeckner E, Bengtsson L, Feichter J, Lelieveld J, Rodhe H (1999) Transient climate change simulations with a coupled atmosphere-ocean gcm including the tropospheric sulfur cycle. J Clim 12:3004-3032

Roeckner E, Baeuml G, Bonventura L, Brokopf R, Esch M, Giorgetta M, Hagemann S, Kirchner I, Kornblueh L, Manizini E, Rhodin A, Schlese U, Schulzweida U, Tompkins A (2003) The atmospheric general circulation model ECHAM5. Part I: Model description, report 349, Max Planck Institute for Meteorology, Hamburg, Germany, available from: http://www.mpimet.mpg.de

Rotstayn L, Lohmann U (2002) Tropical rainfall trends and the indirect aerosol effect. J Clim 15:2103-2116

Shindell D, Levy-II H, Schwarzkopf M, Horowitz L, Lamarque JF, Faluvegi G (2008) Multimodel projections of climate change from short-lived emissions due to human activities. J Geophys Res 113:doi:10.1029/2007JD009152

Stier P, Feichter J, Kinne S, Kloster S, Vignati E, Wilson J, Ganzeveld L, Tegen I, Werner M, Balkanski Y, Schulz M, Boucher O, Minikin A, Petzold A (2005) The aerosol-climate model ECHAM5-HAM. Atmos Chem Phys 5:1125-1156

Streets D, Wu Y, Chin M (2006) Two-decadal trends as a likely explanation of the global dimming/brightening transition. J Geophys Res 33:doi:10.1029/2006GL026471

Stuber N, Ponater M, Sausen R (2001) Is the climate sensitivity to ozone pertubations enhanced by stratospheric water vapour feedback?. Geophys Res Lett 28:2887-2890

Sun Y, Solomon S, Dai AG, Portmann RW (2007) How often will it rain?. J Clim 20(19):4801-4818

Swart R, Amann M, Raed F, Tuinstra W (2004) A good climate for clean air: linkages between climate change and air pollution. An editorial essay. Clim Change 66(3):doi:10.1023/B:CLIM. 0000044677.41293.39

Tegen I, Werner M, Harrison SP, Kohfeld KE (2004) Relative importance of climate and land use in determining present and future global soil dust emission. Geophys Res Lett 31(5):doi: 10.1029/2003GL019216

Tsushima Y, Emori S, Ogura T, Kimoto M, Webb MJ, Williams KD, Ringer MA, Soden BJ, Li B, Andronova N (2006) Importance of the mixed-phase cloud distribution in the control climate for assessing the response of clouds to carbon dioxide increase: a multi-model study. Climate Dynamics 27(2-3): $113-126$

Twomey S (1977) The influence of pollution on the shortwave albedo of clouds. J Atmos Sci 34:1249-1152

Unger N, Shindell D, Koch D, Amann M, Cofala J, Streets D (2006) Influences of man-made emissions and climate change of tropospheric ozone, methane and sulfate at 2030 from a broad range of possible futures. J Geophys Res 111:doi:10.1029/ 2005JD006518

Uppala SM, Kallberg PW, Simmons AJ, Andrae U, Da Costa Bechtold V, Fiorino M, Gibson JK, Haseler J, Hernandez A, Kelly GA, Li X, Onogi K, Saarinen S, Sokka N, Allan RP, Andersson E, Arpe K, Balmaseda MA, Beljaars ACM, Van De Berg L, Bidlot J, Bormann N, Caires S, Chevallier F, Dethof A, Dragosavac M, Fisher M, Fuentes M, Hagemann S, Holm E, Hoskins BJ, Isaksen L, Janssen PAEM, Jenne R, Mcnally AP, Mahfouf J-F, Morcrette J-J, Rayner NA, Saunders RW, Simon P, Sterl A, Trenberth KE, Untch A, Vasiljevic D, Viterbo $\mathrm{P}$ and Woollen J (2005) The ERA-40 re-analysis. Q J R Meteorol Soc 131:2961-3012

Webb MJ, Senior CA, Sexton DMH, Ingram WJ, Williams KD, Ringer MA, McAvaney BJ, Colman R, Soden BJ, Gudgel R, Knutson T, Emori S, Ogura T, Tsushima Y, Andronova N, Li B, Musat I, Bony S, Taylor KE (2006) On the contribution of local 
feedback mechanisms to the range of climate sensitivity in two GCM ensembles. Clim Dyn 27(1):17-38

Wentz F, Ricciardulli L, Hilburn K, Mears C (2007) How much more rain will global warming bring? Science 317:233-235

WHO (2003) Health aspects of air pollution with particulate matter, ozone and nitrogen dioxide. Report on a WHO Working group, Bonn, Germany, available at: http://www.euro.who.int/ document/e79097.pdf

Wild M, Gilgen H, Roesch A, Ohmura A, Long C, Dutton E, Forgan B, Kallis A, Russak V, Tsvetkov A (2005) From dimming to brightening: Decadal changes in solar radiation at earth's surface. Science 308(5723):847-850 